\title{
Effect of Autoclaving Time on Corrosion Resistance of Sandblasted Ti G4 in Artificial Saliva
}

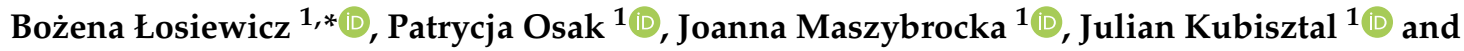 \\ Sebastian Stach 2 (D) \\ 1 Institute of Materials Engineering, Faculty of Science and Technology, University of Silesia in Katowice, \\ 75 Pułku Piechoty 1A, 41-500 Chorzów, Poland; patrycja.osak@us.edu.pl (P.O.); \\ joanna.maszybrocka@us.edu.pl (J.M.); julian.kubisztal@us.edu.pl (J.K.) \\ 2 Institute of Biomedical Engineering, Faculty of Science and Technology, University of Silesia in Katowice, \\ Będzińska 39, 41-200 Sosnowiec, Poland; sebastian.stach@us.edu.pl \\ * Correspondence: bozena.losiewicz@us.edu.pl; Tel.: +48-32-3497-527
}

Received: 5 August 2020; Accepted: 16 September 2020; Published: 18 September 2020

check for updates

\begin{abstract}
Titanium Grade 4 (Ti G4) is the most commonly used material for dental implants due to its excellent mechanical properties, chemical stability and biocompatibility. A thin, self-passive oxide layer with protective properties to corrosion is formed on its surface. However, the spontaneous $\mathrm{TiO}_{2}$ layer is chemically unstable. In this work, the impact of autoclaving time on corrosion resistance of Ti G4 in artificial saliva solution with $\mathrm{pH}=7.4$ at $37^{\circ} \mathrm{C}$ was studied. Ti G4 was sandblasted with white $\mathrm{Al}_{2} \mathrm{O}_{3}$ particles and autoclaved for 30-120 min. SEM, EDS, 2D roughness profiles, confocal laser scanning microscopy, and a Kelvin scanning probe were used for the surface characterization of the Ti G4 under study. In vitro corrosion resistance tests were conducted using open circuit potential, polarization curves, and electrochemical impedance spectroscopy measurements. It was found that $\mathrm{Sa}$ parameter, electron work function, and thickness of the oxide layers, determined based on impedance measurements, increased after autoclaving. The capacitive behavior and high corrosion resistance of tested materials were revealed. The improvement in the corrosion resistance after autoclaving was due to the presence of oxide layers with high chemical stability. The optimal Ti G4 surface for dentistry can be obtained by sandblasting with $\mathrm{Al}_{2} \mathrm{O}_{3}$ with an average grain size of $53 \mu \mathrm{m}$, followed by autoclaving for $90 \mathrm{~min}$.
\end{abstract}

Keywords: autoclaving; corrosion resistance; oxide layer; saliva; titanium

\section{Introduction}

Titanium belongs to the vital elements. It is characterized by high corrosion resistance, low specific gravity and mechanical properties similar to bone tissue. This metal does not cause toxic reactions and is highly biocompatible with living tissue. There are also no reports of allergic reactions to titanium. Due to these unique properties, titanium and its alloys are widely used in modern implantology, particularly for the production of dental implants [1-4]. Other popular metals in dentistry are also silver, gold and palladium. However, studies have shown that these noble metals give a positive response in allergic patch tests, which excludes the possibility of their use on dental implants $[5,6]$. So far, no material with full biological compatibility has been produced that would ensure complete anastomosis and coupling with the living structures of the human body [3].

The precisely defined and designed surface structure of biomaterials is currently the main development strategy for the latest generation of dental implants. Since Brånemark, called the "father of modern dental implantology", discovered the osseointegrative properties of titanium in 1952 [7], many attempts have been made to design the perfect surface for fast osteoconductivity and 
osseointegration, enabling immediate functional loading of the implant and long-term anchoring of implants. A particularly important role in achieving the initial stability of the implant-bone tissue connection plays the chemical and phase composition as well as the topography of the implant surface $[8,9]$. Surface roughness and porosity has been proven to be an essential requirement for long-term implants that are used in dentistry [1]. These factors determine the good mechanical stability of the implant as well as the proper course of the implant osseointegration process with bone tissue [8-12]. Therefore, the surface of titanium dental implants has been modified over the years $[2,4,9,11,13]$.

The oldest surface of titanium dental implants, which appeared on the market in the 70s of the last century, is the machine surface with the least roughness with a $R a$ of only $0.1-0.8 \mu \mathrm{m}[9,14-17]$. The machine surface is obtained by cutting titanium during implant production and exhibits less osseointegration ability compared to implants with a developed surface. It is an isometric, anisotropic surface with present oriented and parallel furrows. Such a smooth surface limits the osseointegration process by extending the implant's stabilization time and increasing the risk of post-implantation complications. The latest research in the field of implantoprosthetics shows that stabilization of collagen scaffolding, facilitating the accumulation of bone tissue on the implant surface, occurs more easily on the rough surface of the intraosseous implant. The bone adhesion surface to the porous surface of the implant is thus increased. That is why almost all the latest generation dental implants have a porous surface obtained using various technologies specific for a given system and manufacturer. Therefore, titanium implants with a larger surface development are sought after, which will increase the potential for biomechanical contact at the implant-bone border and affect the rate of protein adsorption [18].

Intensive efforts have been made to develop titanium implants with the surface covered with titanium plasma-sprayed coating (TPS) [19,20], the surface with hydroxyapatite (HA) [13,21,22], the sandblasted surface [23-26], the double acid-etched surface (DE) $[23,25,27,28]$, the sandblasted and etched surface (sandblasted large-grit acid-etched, SLA) [25,29-31], the hydrophilic surface (SLActive) $[25,30,32,33]$, or an oxidized (anodized) surface, which was introduced in 2001 and is referred to as TiUnite [28,34-37]. Recently, it has also been proposed to modify the surface of titanium implants with biologically active substances [38,39]. The latter type of titanium implant surface is still in the experimental phase.

Currently, the sandblasting is one of the most commonly used processes during the final surface treatment of dental implants. This type of surface is rough, irregular, with numerous craters formed as a result of sandblasting and is characterized by isotropy. The surface development of the sandblasted surface is $34 \%$ larger compared to the machine surface [26]. During the sandblasting process, the titanium surface is bombarded with an abrasive, usually corundum, which provides the best osseointegration effects. The grain size of $\mathrm{Al}_{2} \mathrm{O}_{3}$ should be a minimum of $25 \mu \mathrm{m}$ and a maximum of $250 \mu \mathrm{m}$. The best results of osseointegration are obtained by using grain sizes of $25-75 \mu \mathrm{m}$. After the sandblasting process, small amounts of $\mathrm{Al}_{2} \mathrm{O}_{3}$ may remain on the titanium surface, which may impede healing of bone tissue. Sandblasting with $\mathrm{TiO}_{2}$ of $10-125 \mu \mathrm{m}$ grain size, calcium phosphate powders in the form of hydroxyapatite, or $\beta$-tricalcium phosphate $(\beta-\mathrm{TCP})$ is also used. As the grain size of the abrasive increases, the surface roughness increases. For the sandblasted surface, $R a$ is $1-3 \mu \mathrm{m}$.

In the field of implantoprosthetics, there is also an attempt to shorten the time between implantation and patient loading. Therefore, implants are sought that will guarantee faster healing of bone tissue. There is a tendency to introduce a modification of the surface of titanium implants that will ensure rapid osseointegration, thus enabling immediate functional loading of the implant. Initially, this goal was pursued by increasing the surface roughness of the implants [14-17]. However, too large a surface development of the implant causes the opposite effects. Optimal surfaces appear to be of average roughness as for the sandblasted surface, and with physico-chemical properties that can stimulate bone tissue to grow.

The type of implant surface is an important, but not the only, factor that has a significant impact on the success of the implantation and on the processes that occur during implant osseointegration. 
A key role in protecting titanium and its alloys against harmful factors of the biological environment is played by a self-passive oxide layer with strong barrier properties in a biological environment, which is also self-healing. However, it should be noted that the self-passive oxide layer on the surface of titanium and its alloys has a discontinuous structure and is chemically unstable, which is of great importance for the protective function that the passive layer is to perform in a biological environment. Due to the extremely fast rate of formation, the self-passive $\mathrm{TiO}_{2}$ layers on titanium easily become amorphous, showing high corrosion resistance, which, however, decreases with the crystallization of the oxide layer [39]. This fact suggests that the surface of titanium and its alloys should be subject to additional modification, which by changing the chemical composition, structure and morphology of the surface will improve the corrosion resistance, bioactivity and osseointegration.

In order to obtain a stable oxide layer ensuring high corrosion resistance of titanium implants, various sterilization methods are used, such as steam autoclave sterilization, sterilization using ethylene oxide and UV radiation [40-46]. However, the most popular method of sterilization of dental implants and medical devices is autoclaving. This method does not change the chemical composition and structure of the material subjected to sterilization compared to other methods. In hot water or steam, heat is sterilized faster and more efficiently than in dry air due to the several times higher thermal conductivity of water compared to air [45]. Sterilization with UV rays affects changes in the $\mathrm{TiO}_{2}$ layer nanostructure [42]. Steam autoclave sterilization is the most effective method of heat exchange, it allows the safety of the medical device during its use, in particular in contact with blood.

Corrosion of the passive oxide layer on the surface of titanium and its alloys in body fluids is an electrochemical process. Hence, electrochemical techniques, and especially impedance techniques, are suitable for testing the corrosion resistance of passive layers. In the system of metallic electrode-passive layer-biological environment, a number of phenomena, such as passive dissolution, transpassive dissolution, uniform corrosion, local corrosion, and adsorption, can occur. Electrochemical impedance spectroscopy (EIS) as the only electrochemical method allows quantitative determination of the kinetics of these processes in in situ tests with simultaneous characteristics of the capacitive behavior of the tested systems. Innovative impedance studies presented in our earlier works have shown that EIS can be proposed as a modern tool in in vitro studies of corrosion resistance of titanium and its alloys in body fluids, which provides information on the detailed mechanisms and kinetics of electrochemical corrosion and the properties of passive layers [40,41,47,48].

The most popular solution used for in vitro corrosion resistance tests of titanium dental implants is saline [24,49]. These biomaterials show higher corrosion resistance than surgical steel and cobalt-chromium alloys [2]. There are only few literature reports on the selection of the appropriate type and sterilization time to increase the corrosion resistance of titanium after the sandblasting process $[43,44,46]$. Since the corrosion resistance of titanium implants largely depends on the thickness of the oxide layer, the main purpose of the research in this paper was to assess for the first time the effect of steam autoclave sterilization time on the in vitro corrosion resistance of sandblasted titanium implants in artificial saliva solution. Classical corrosion resistance test methods, such as the open circuit potential method and polarization curve method, as well as the complementary EIS method, were used in in vitro tests.

\section{Materials and Methods}

The subject of the study was titanium with a purity grade 4 (Ti G4) produced in the form of a rod (Bibus Metals Ltd., Dabrowa, Poland). Titanium samples in accordance with ISO 5832-2 [50] and ASTM F67 [51] with the chemical composition given in Table 1 and mechanical properties presented in Table 2, were prepared in the form of discs with a diameter of $10 \mathrm{~mm}$ and a height of $5 \mathrm{~mm}$. Table 3 shows the physical properties of Ti G4. Disc-shaped Ti G4 samples were grounded with 80 to 5000\# grit $\mathrm{SiC}$ paper and polished using final OP-S suspension (Struers Inc., Cleveland, OH, USA) to obtain a mirror-like surface. Then, the samples were cleaned for $20 \mathrm{~min}$ in an ultrasonic cleaner in acetone 
and then in ultra-pure water with a resistivity of $18.2 \mathrm{M} \Omega \mathrm{cm}$ at $25^{\circ} \mathrm{C}$ (Milli-Q Advantage A10 Water Purification System, Millipore SAS, Molsheim, France). The cleaning procedure was repeated twice.

Table 1. Chemical composition of Ti G4.

\begin{tabular}{cccccc}
\hline $\mathbf{C}$ & $\mathbf{F e}$ & $\mathbf{O}$ & $\mathbf{H}$ & $\mathbf{N}$ & $\mathbf{T i}$ \\
\hline$<0.080 \%$ & $<0.500 \%$ & $<0.400 \%$ & $<0.008 \%$ & $<0.050 \%$ & $98.962 \%$ \\
\hline
\end{tabular}

Table 2. Mechanical properties of Ti G4.

\begin{tabular}{cccc}
\hline Tensile Strength (MPa) & Yield Point (MPa) $\mathbf{0 . 2 \%}$ & HV5 Hardness & Elongation \\
\hline$>800$ & $>700$ & $>280$ & $>10 \%$ \\
\hline
\end{tabular}

Table 3. Physical properties of Ti G4.

\begin{tabular}{ccc}
\hline Melting Temperature & Density & Modulus of Elasticity \\
\hline $1610^{\circ} \mathrm{C}$ & $4.5 \mathrm{~g} \mathrm{~cm}^{-3}$ & $114 \mathrm{GPa}$ \\
\hline
\end{tabular}

Polished and cleaned Ti G4 samples were sandblasted using white corundum of FEPA Grit F220 [52]. Chemical composition of the corundum used is given in Table 4. The hardness of white $\mathrm{Al}_{2} \mathrm{O}_{3}$ on the Mohs scale was 9.20-9.30. The specific density and the bulk density of white corundum was 3.95(50) and 1.52-1.85 $\mathrm{g} \cdot \mathrm{cm}^{-3}$, respectively. Sandblasting parameters were pressure $0.6 \mathrm{MPa}$, sandblasting time $15 \mathrm{~s}$, distance of the sandblasting nozzle from the surface of the blasted titanium about $1.5 \mathrm{~cm}$. Sandblasted Ti G4 samples were sonicated for $20 \mathrm{~min}$ sequentially in acetone and then in ultra-pure water to remove corundum residues from the surface.

Table 4. Chemical composition of white corundum used for the sandblasting of Ti G4.

\begin{tabular}{cc}
\hline Component & Content (\%) \\
\hline $\mathrm{Al}_{2} \mathrm{O}_{3}$ & 99.702 \\
$\mathrm{SiO}_{2}$ & 0.035 \\
$\mathrm{Fe}_{2} \mathrm{O}_{3}$ & 0.045 \\
$\mathrm{TiO}_{2}$ & 0.008 \\
$\mathrm{CaO}$ & 0.02 \\
$\mathrm{Na}_{2} \mathrm{O}$ & 0.19 \\
\hline
\end{tabular}

Next, steam autoclave sterilization was carried out in distilled water vapour at $134^{\circ} \mathrm{C}$ at a pressure of 2.2 bar for 30, 60, 90, and 120 min using a fully automatic Autoclave Model GR60 DA of Zealway Instrument Inc. (Xiamen, China). Samples were autoclaved in sterilization sleeves containing chemical indicators in the form of a pink rectangle, which changed to brown after the autoclaving process.

The titanium surface morphology before and after autoclaving was examined by scanning electron microscopy (SEM). Observations were carried out using a JEOL JSM-6480 microscope (JEOL Ltd., Tokyo, Japan) at the voltage of $20 \mathrm{kV}$ and the current intensity of $75 \mathrm{~mA}$, additionally equipped with an energy dispersion spectroscopy (EDS) system, which allowed for the determination of the surface chemical composition.

Confocal laser scanning microscopy (CLSM) was used to assess the surface topography of Ti G4. The research used the LEXT OLS4000 confocal laser measuring microscope (Olympus Polska Ltd., Warszawa, Poland).

The Mitutoyo Surftest SJ-500 profilometer (Mitutoyo Polska Ltd., Wrocław, Poland) was used to carry out the observation of the cross-sectional profile of the sliding track. 
Ti G4 samples before and after autoclaving were subjected to electrochemical tests in artificial saliva solution (ASS) of $\mathrm{pH}=7.4(1)$ at $37(1){ }^{\circ} \mathrm{C}$ using the Autolab/PGSTAT20 computer-controlled electrochemical system (Metrohm Autolab B.V., Utrecht, The Netherlands).

Chemical composition of the ASS is shown in Table 5. To adjust the $\mathrm{pH}$ of the ASS, $4 \%$ $\mathrm{NaOH}$ solution and $1 \% \mathrm{C}_{3} \mathrm{H}_{6} \mathrm{O}_{3}$ solution were used in accordance with ISO 10271 [49]. Before each measurement, the ASS was deaerated with argon (99.999\% purity) for $20 \mathrm{~min}$. The three-electrode system was used in electrochemical studies. The working electrode (WE) was a titanium disk with a geometric surface area of $0.785 \mathrm{~cm}^{2}$. One side of the WE and its sidewalls were coated with a non-conductive epoxy resin to protect against contact with the ASS. The counter electrode (CE) was a $4 \mathrm{~cm}^{2}$ platinum mesh. The reference electrode (RE) was a saturated calomel electrode (SCE) connected to the ASS using Luggin capillary. Open circuit potential, $E_{\mathrm{OC}}$, was stabilized for $2 \mathrm{~h}$ according to ISO 10271 [49].

Table 5. Chemical composition of artificial saliva solution.

\begin{tabular}{cc}
\hline Component & Content $\left(\mathrm{g} \mathrm{dm}^{-3}\right)$ \\
\hline $\mathrm{NaCl}$ & 0.70 \\
\hline $\mathrm{KCl}$ & 1.20 \\
\hline $\mathrm{Na}_{2} \mathrm{HPO}_{4}$ & 0.26 \\
\hline $\mathrm{NaHCO}_{3}$ & 1.50 \\
\hline $\mathrm{KSCN}$ & 0.33 \\
\hline
\end{tabular}

Then, the polarization curves in the range of potentials close to the $E_{\mathrm{OC}}$ were recorded at the polarization rate of $v=1 \mathrm{mV} \mathrm{s}^{-1}$ and subjected to the Savitzky-Golay smoothing algorithm available in the General Purpose Electrochemical System software [53]. Based on the obtained $\log |j|=f(E)$, the Tafel extrapolation method was carried out and the parameters of corrosion resistance as corrosion potential $\left(E_{\text {cor }}\right)$, corrosion current density $\left(j_{\text {cor }}\right)$, anodic $\left(b_{\mathrm{a}}\right)$ and cathodic $\left(b_{\mathrm{c}}\right)$ Tafel slopes, polarization resistance $\left(R_{\mathrm{p}}\right)$, and corrosion rate $(C R)$ at the $E_{\text {cor }}$, were determined.

The EIS measurements were performed at the $E_{\mathrm{cor}}$ in the range of the frequencies studied from $10^{5}$ to $10^{-3} \mathrm{~Hz}$ with frequency resolution $0.003 \%$. Ten frequencies per decade were scanned using an excitation signal in the form of a sine wave with an amplitude of $10 \mathrm{mV}$. The Kramers-Kronig (K-K) relations were used to assess the correctness of the obtained impedance data [54]. The experimental EIS data were analyzed based on the equivalent electrical circuit concept. Simulation of the equivalent circuit responses and fitting the circuit parameters to the measured data was realized using the EQUIVCRT program [54]. The complex non-linear least squares (CNLS) method with modulus weighting was used. The statistical F test was used to check the importance of the parameters of the selected circuit.

The local contact potential difference $\left(V_{\mathrm{CPD}}\right)$ measurements were carried out in air by the scanning Kelvin probe (SKP) method. The PAR Model 370 Scanning Electrochemical Workstation (Princeton Applied Research, Oak Ridge, TN, USA) was used. The distance between the tungsten microprobe-tip and the sample surface was ca. $100 \mu \mathrm{m}$. An area of $1000 \times 1000 \mu \mathrm{m}^{2}$ was scanned. The tip-sample arrangement was assumed to be a capacitor, and the $V_{\mathrm{CPD}}$ was determined from the difference of work function (WF) for sample and tip [55]:

$$
V_{\mathrm{CPD}}=\frac{W F_{\text {sample }}-W F_{\text {tip }}}{e}
$$

where $e$ denotes the elementary charge. 


\section{Results and Discussion}

\subsection{SEM/EDS Observations}

The material in the initial state was the Ti G4 dental metal with machine surface subsequently sandblasted with white $\mathrm{Al}_{2} \mathrm{O}_{3}$ particles with a grain size of 53-75 $\mu \mathrm{m}$. The average micron size of the grain was $53 \mu \mathrm{m}$. The SEM image of $\mathrm{Al}_{2} \mathrm{O}_{3}$ particles used for sandblasting shows the sharp-edged shape of the grains (Figure 1a). This is due to the fact that the grains of very fine abrasive material always break according to specific splitting planes as a result of grinding. Therefore, they have shapes similar to prisms with a triangular or quadrangular base, pyramids with the same base, octagons, and cubes. The use of sharp-edged grains reduces abrasive consumption during sandblasting.

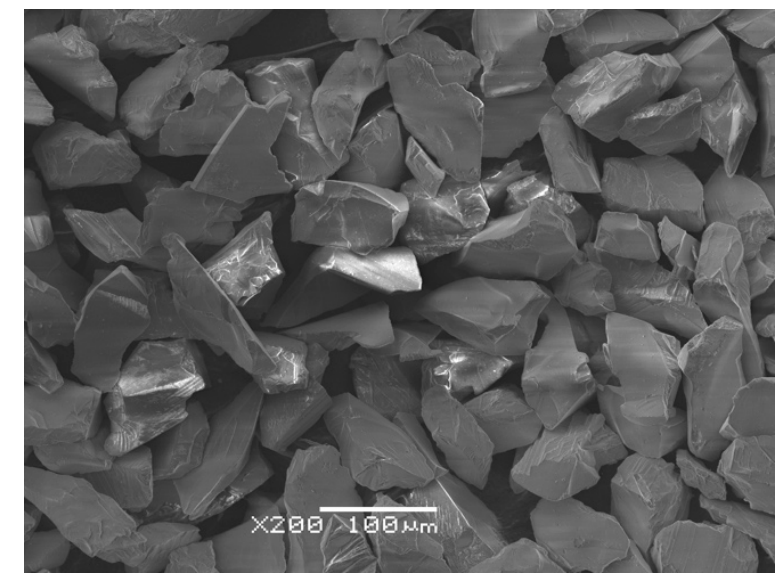

(a)

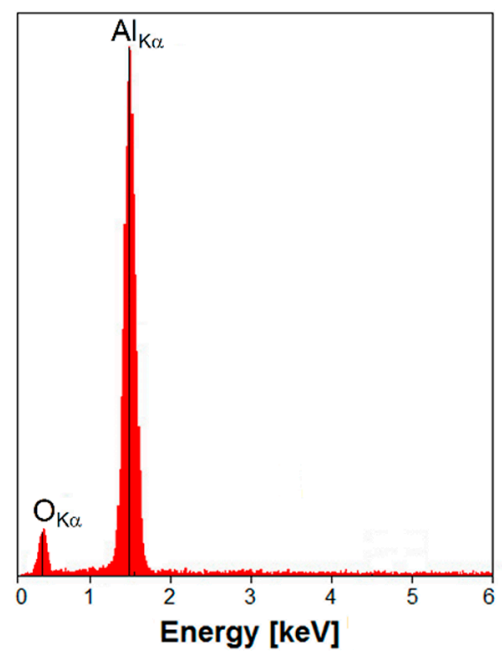

(b)

Figure 1. (a) SEM image of white $\mathrm{Al}_{2} \mathrm{O}_{3}$ particles used for sandblasting; (b) EDS spectrum of $\mathrm{Al}_{2} \mathrm{O}_{3}$.

EDS microanalysis allowed to identify the chemical elements contained in the tested white corundum in the form of powder. The EDS spectrum depending on the number of counts as a function of radiation energy for $\mathrm{Al}_{2} \mathrm{O}_{3}$ is shown in Figure $1 \mathrm{~b}$. Qualitative EDS analysis confirmed the presence of elements with the atomic number $Z$ of 8 and 13, i.e., oxygen and aluminum, respectively. No other elements that could originate from impurities in the abrasive used for sandblasting of the Ti G4 were revealed. The obtained results confirm that the corundum used in the sandblasting process was characterized by high purity.

The morphology of the Ti G4 machine surface is poorly developed as shown in Figure 2a. On a flat surface, oriented and parallel grooves $\leq 10 \mu \mathrm{m}$ can be observed. These scarce morphological motifs were created during the titanium cutting process in which the cutting tool created shallow grooves and left some melted metal. The machine surface is isometric, anisotropic and the least rough of the titanium implant surfaces used in implantology with the average thickness of the self-passive $\mathrm{TiO}_{2}$ layer equal to $17 \mathrm{~nm}[9,14-17]$. Such a little advanced surface is characterized by weaker osseointegration in comparison with implants with more developed surfaces.

Analysis of the local chemical composition of the Ti G4 machine surface showed the presence of peaks originated from elements with the atomic number $Z$ of 8 and 22, i.e., oxygen and titanium, respectively (Figure $2 b$ ). Detected peak of $O$ is of very low intensity due to the fact that oxygen is associated with the presence of the self-passive oxide layer on the $\mathrm{Ti}$ G4 substrate. 


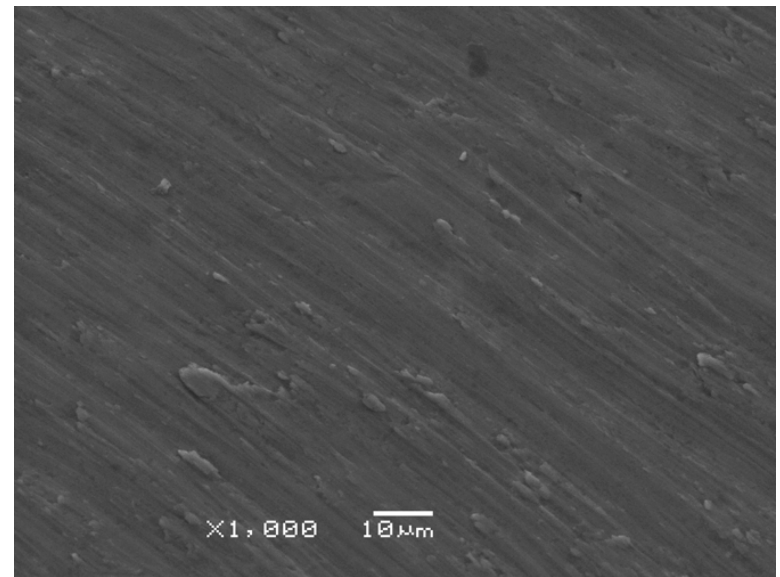

(a)

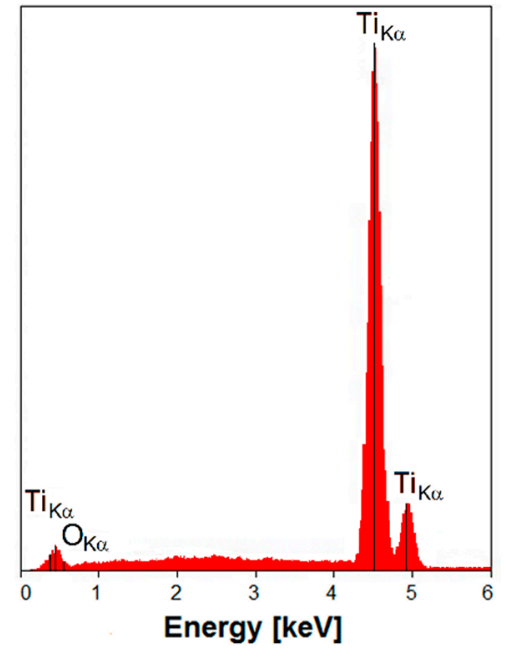

(b)

Figure 2. (a) SEM image of the Ti G4 machine surface; (b) EDS spectrum in the micro-region of the machine surface.

In the next stage of research, sandblasting was carried out, which was aimed at cleaning and leveling the machine surface of Ti G4 and obtaining the appropriate roughness using white corundum under compressed air pressure. Sandblasting as a technological process has been patented by Tilghman in 1870 [56]. The SEM image of the Ti G4 machine surface after sandblasting is shown in Figure 3a. The Ti G4 topography became irregular and rough as a result of the bombardment of the titanium surface with $\mathrm{Al}_{2} \mathrm{O}_{3}$ grains. As a result of plastic deformation, dents are observed in some places on the titanium surface after sandblasting, in others, bulges increase. Microscopic observation of Ti G4 surface shows the presence of small craters and microcracks initiated on the surface during the sandblasting process. This phenomenon is the result of the compressive residual stress after sandblasting and surface hardening [24]. Despite a rougher surface, no macro-scale cracks form on the surface because, after sandblasting, a fine-grained structure is created that limits crack initiation. The sandblasted surface is isotropic without the dominant structure direction. The development of the Ti G4 sandblasted surface compared to the machine surface provides better osseointegration effects [57].

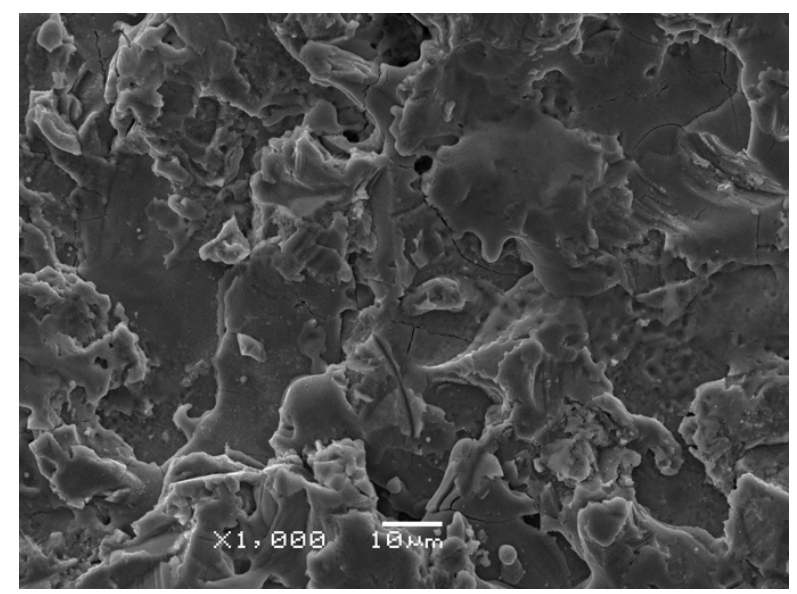

(a)

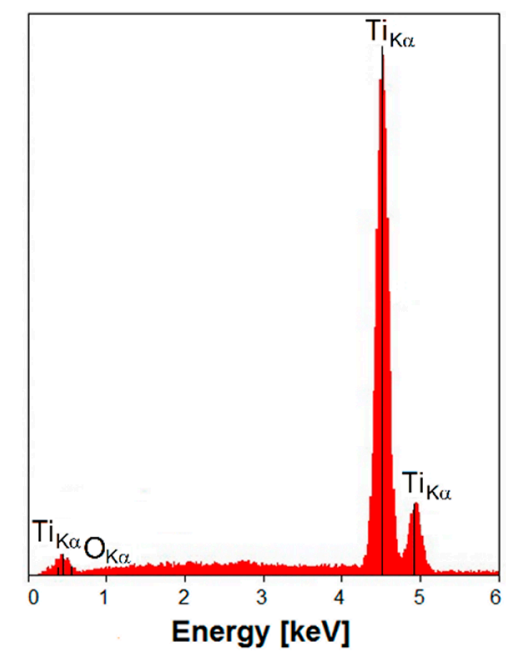

(b)

Figure 3. (a) SEM image of the Ti G4 machine surface after sandblasting; (b) EDS spectrum in the micro-region of the sandblasted surface. 
EDS spectrum of the Ti G4 machine surface after sandblasting indicated the presence of Ti and O only (Figure 3b). Very low intensity of the peak originated from $\mathrm{O}$ is related to low oxygen content in the self-passive $\mathrm{TiO}_{2}$ layer on the sandblasted titanium with the average thickness of $2-5 \mathrm{~nm}$ [57]. No peaks originating from $\mathrm{Al}$ were detected that would indicate that $\mathrm{Al}_{2} \mathrm{O}_{3}$ particles stuck into the titanium surface during the sandblasting process. Such an unfavorable phenomenon was previously observed in the literature when corundum $90 \mu \mathrm{m}$ was used for sandblasting titanium dental implants [58]. Alumina particles were identified by energy dispersive $X$-ray spectroscopy on the sandblasted surface of titanium and attributed to sandblasting residues that could not be removed even after acid etching. Remaining even small amounts of $\mathrm{Al}_{2} \mathrm{O}_{3}$ on the sandblasted surface of titanium can impede bone healing. The result obtained in this study suggests that the proposed conditions of sandblasting ensure the optimum amount of compressive residual stress induced by sandblasting, which is controlled by air pressure and the size and shape of the abrasive particles. The stresses generated harden the titanium and impede the stick of $\mathrm{Al}_{2} \mathrm{O}_{3}$ particles into the surface despite their sharp shapes, as shown in Figure 1a. The surface topography obtained in this way can positively affect cell proliferation, as well as increase the mechanical stability of Ti G4 implants after the implantation process [57].

\subsection{Surface Roughness}

The surface quality of the biomaterial significantly affects the functional properties of dental implants, which are expressed, among others through corrosion resistance. The geometrical structure of the surface (GSS) is one of the most important factors determining the quality of a given surface. It defines a set of all overlapping inequalities resulting from machining processes and material consumption. These inequalities have different shapes, dimensions and location. From a metrological point of view, one of the most important components of the surface layer is roughness which is a predetermined and predictable parameter. The selection of appropriate surface treatment parameters results in the expected roughness. Roughness is of paramount importance in dental implants, as it directly affects their durability. Roughness parameters refer to specific profile features. Full surface characteristics therefore require a set of parameters describing the height of the inequalities, their shape and the spacing between them. These parameters can be distinguished over thirty, while in everyday practice only a few are used.

Detailed characteristics of the GSS for the machine and sandblasted Ti G4 was carried out based on measurements of surface microgeometry in the two-dimensional (2D) system. In order to determine the roughness parameters, the measured profiles were leveled. Symmetrical surface profiles were obtained. Basic surface texture parameters were determined according to ISO 4287 [59] and the results obtained are presented in Table 6 . Determined amplitude parameters were separated into two groups depending on the type of profile from which they were calculated. $P$ parameters were calculated on the primary profile (raw profile after measurement). $R$ parameters were calculated on the roughness profile. Definitions for $P$ and $R$ parameters are given in ISO 4287 [59]. Expanded surface texture parameters were determined according to ISO 13565-2 [60]. The discussion of the results was limited to profile height parameters with the use of which it is possible to analyze the topography and development of the surface of the tested materials.

The 2D roughness profile for the Ti G4 with machine surface is shown in Figure 4a. The Psk parameter meaning skewness of the primary profile is -0.07 which points to a symmetrical profile (Table 6). The arithmetic mean deviation of the roughness profile $R a$ of the machine surface is $0.12 \mu \mathrm{m}$, which indicates a smooth surface of the material (Table 6). As shown in Figure 4a, some sites on the surface were as deep as almost $1 \mu \mathrm{m}$ from the mean line, which was consistent with SEM observations (Figure 2a). The Ra parameter is privileged and is most often used. In practice, it is the distance between two parallel lines limiting the surface area of the profile areas filled with material above the average line and the profile areas without material below the average line. It is the height of the space around the average line formed after "leveling" hills and valleys. The Ra parameter in $\mu \mathrm{m}$ better reflects the size of the roughness on larger surfaces, as it eliminates the influence of single, irregular 
hills or pits. The $R z$ parameter, which for the Ti G4 with machine surface was $1.23 \mu \mathrm{m}$, is also preferred (Table 6). This is the average of the difference of the five largest heights and the lowest valleys along the length of the elementary segment. The $R z$ parameter is also sometimes referred to as "roughness height by 10 points" and reflects very accurately the roughness tested, which is often a drawback, because the overall roughness image can be distorted by any accidental excessive hill or valley, significantly affecting the measurement result. It seems that $\mathrm{R} a$ parameter is better for holistic roughness recognition, while $R z$ parameter is more appropriate for local field assessment.

Table 6. Basic surface texture parameters for the Ti G4 with machine and sandblasted surface according to ISO 4287 [59], where: $P a$-arithmetic mean deviation of the primary profile, $P q$-root mean square deviation of the primary profile, $P p$-maximum peak height of the primary profile, $P v$-maximum valley depth of the primary profile, $P t$-total height of the primary profile, Psk-skewness of the primary profile, $P k u$-kurtosis of the primary profile, $R a$-arithmetic mean deviation of the roughness profile, $R z$-maximum height of the roughness profile, and $R p$-maximum peak height of the roughness profile.

\begin{tabular}{|c|c|c|c|c|}
\hline \multirow{3}{*}{ Parameter } & \multicolumn{4}{|c|}{ Ti G4 } \\
\hline & \multicolumn{2}{|c|}{ Machine Surface } & \multicolumn{2}{|c|}{ Sandblasted Surface } \\
\hline & Value & $\begin{array}{l}\text { Standard } \\
\text { Deviation }\end{array}$ & Value & $\begin{array}{l}\text { Standard } \\
\text { Deviation }\end{array}$ \\
\hline$P a\left(\mu \mathrm{m}^{2} \mathrm{~m}^{-1}\right)$ & 0.13 & 0.01 & 1.89 & 0.11 \\
\hline$P q(\mu \mathrm{m})$ & 0.17 & 0.01 & 2.33 & 0.12 \\
\hline$P p(\mu \mathrm{m}]$ & 0.87 & 0.28 & 7.23 & 1.02 \\
\hline$P v(\mu \mathrm{m})$ & 0.78 & 0.03 & 7.55 & 0.96 \\
\hline$P t(\mu \mathrm{m}]$ & 1.65 & 0.25 & 14.80 & 1.94 \\
\hline Psk & -0.07 & 0.35 & -0.08 & 0.10 \\
\hline$P k u$ & 4.34 & 1.35 & 2.79 & 0.39 \\
\hline$R a(\mu \mathrm{m})$ & 0.12 & 0.01 & 1.65 & 0.07 \\
\hline$R z(\mu \mathrm{m}]$ & 1.23 & 0.11 & 11.20 & 0.83 \\
\hline$R p(\mu \mathrm{m})$ & 0.69 & 0.17 & 5.37 & 0.51 \\
\hline
\end{tabular}

The graphical interpretation of the research was presented in the form of a percentage distribution of the height ordinate on a unit surface (Figure 4b). The machine surface of Ti G4 is characterized by a symmetrical distribution of the height ordinate. Values of the height ordinate are in the range of 0.448 to $1.7 \mu \mathrm{m}$. The highest percentage of about $21 \%$ is observed for the height from 0.895 to $0.985 \mu \mathrm{m}$. The percentage of the maximum value of the height ordinate on the machine surface is only about $0.1 \%$. The results obtained are in great agreement with the results of SEM observations in Figure 2a, which confirmed the small differentiation of the Ti G4 machine surface topography.

The surface bearing area ratio curve shown in Figure $4 \mathrm{c}$ was the basis for the determination of expanded surface texture parameters according to ISO 13565-2 [60] which defines a set of $R k$ parameters that can be calculated from a graphical construction on the Abbot-Firestone curve of a S-shape. Height characterization using the linear material ratio curve included the determination of the following parameters: $R k$, core roughness depth, $R p k$, reduced peak height, $R v k$, reduced valley depth, $M r 1$, material portion 1, Mr2, material portion 2, $A 1$, area between the upper intersection line and the material ratio curve, and $A 2$, the area between the material ratio curve and the bottom intersection line. In Figure 4c, the surface division into three parts is visible: the area of the hills with $R p k$ of $0.161 \mu \mathrm{m}$, the area of the profile roughness core for which $R k=0.37 \mu \mathrm{m}$, and the area of the profile valleys which is characterized by $R v k=0.206 \mu \mathrm{m}$. The low value of the $R p k$ parameter indicates a smooth machine surface of Ti G4. The results obtained indicate that in order to use the Ti G4 surface for dental implants, it is necessary to increase the surface roughness. 


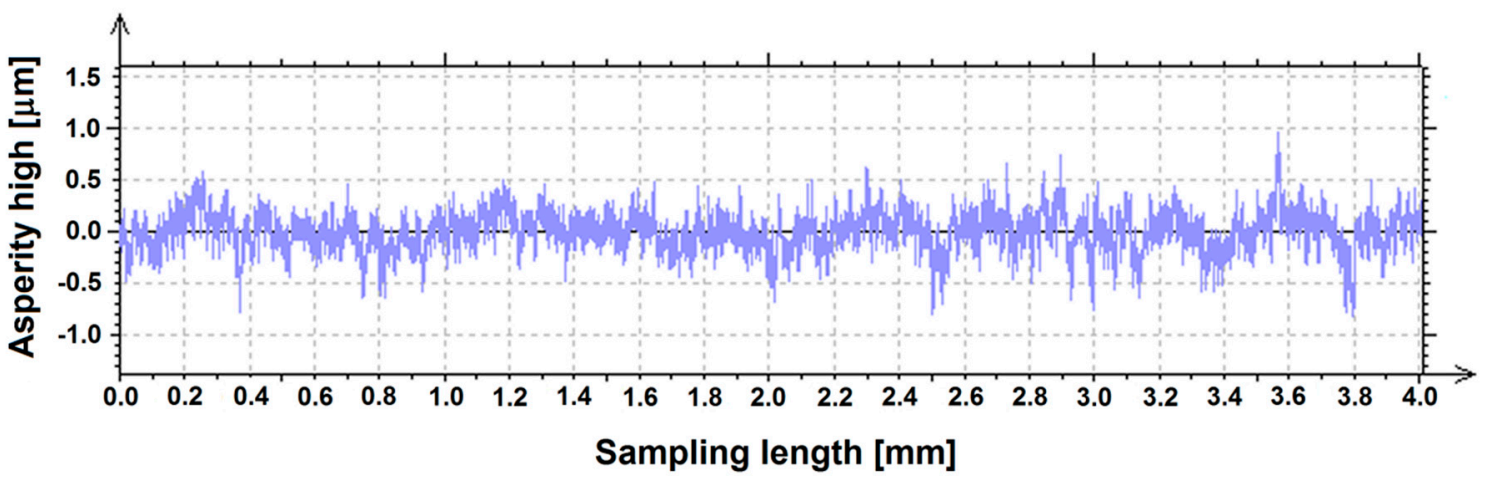

(a)

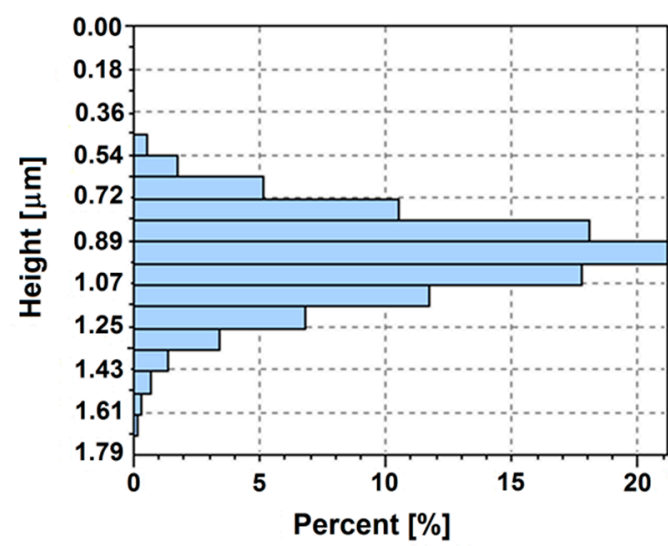

(b)

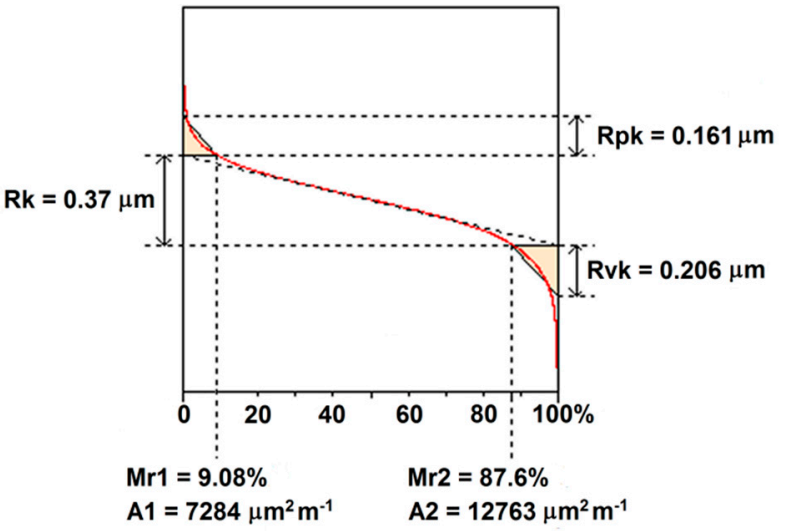

(c)

Figure 4. Sample profile recorded for the Ti G4 with machine surface: (a) Roughness profile; (b) Distribution of the height ordinate; (c) Surface bearing area ratio curve.

The 2D roughness profile for the Ti G4 with sandblasted surface is presented in Figure 5a. After the sandblasting process, a symmetrical profile was obtained, as evidenced by the skewness parameter Psk, which is -0.08 (Table 6). As a result of such a surface treatment of the Ti G4, an increase of the arithmetic mean deviation of the roughness profile by over 13 times compared to the $R a$ for machine surface is observed (Table 6). The maximum height of the roughness profile for the sandblasted Ti G4 also increases by over nine times compared to $R z$ obtained for the machine surface (Table 6). Analysis of the roughness profile indicates an increase in the topography development for the surface after sandblasting, for which numerous sites with a depth of almost $10 \mu \mathrm{m}$ from the mean line are observed in accordance with the SEM observations (Figure 3a).

After the sandblasting process, a surface with symmetrical distribution of the height ordinate was obtained (Figure $5 \mathrm{~b}$ ). The height ordinate values changes from 0 to $14.9 \mu \mathrm{m}$. The highest percentage of about $11 \%$ is seen for the height ordinate from 5.98 to $8.22 \mu \mathrm{m}$. The percentage of the maximum value of the height ordinate on the sandblasted surface is only about $0.1 \%$. These results confirm the SEM observations in Figure 3a, where more advanced topography of Ti G4 sandblasted surface is observed with numerous, evenly distributed, hills and valleys of varying heights.

Figure 5c presents the surface bearing area ratio curve for the Ti G4 after sandblasting. Height characterization using the linear material ratio curve was carried out based on the average height of protruding peaks above roughness core profile of $R p k=1.33 \mu \mathrm{m}$, depth of the roughness core profile of $R k=4.55 \mu \mathrm{m}$, and average depth of valleys projecting through roughness core profile of $R v k=1.78 \mu \mathrm{m}$. The $R k$ parameter increased by more than 12 times and both $R p k$ and $R v k$ parameters more than eight times compared to the smooth machine surface of Ti G4. The obtained results confirm the increase 
in surface roughness of Ti G4 as a result of sandblasting which is desirable for metallic biomaterials. According to literature data, the optimal $R a$ value between 1 and $2 \mu \mathrm{m}$ is required [17].

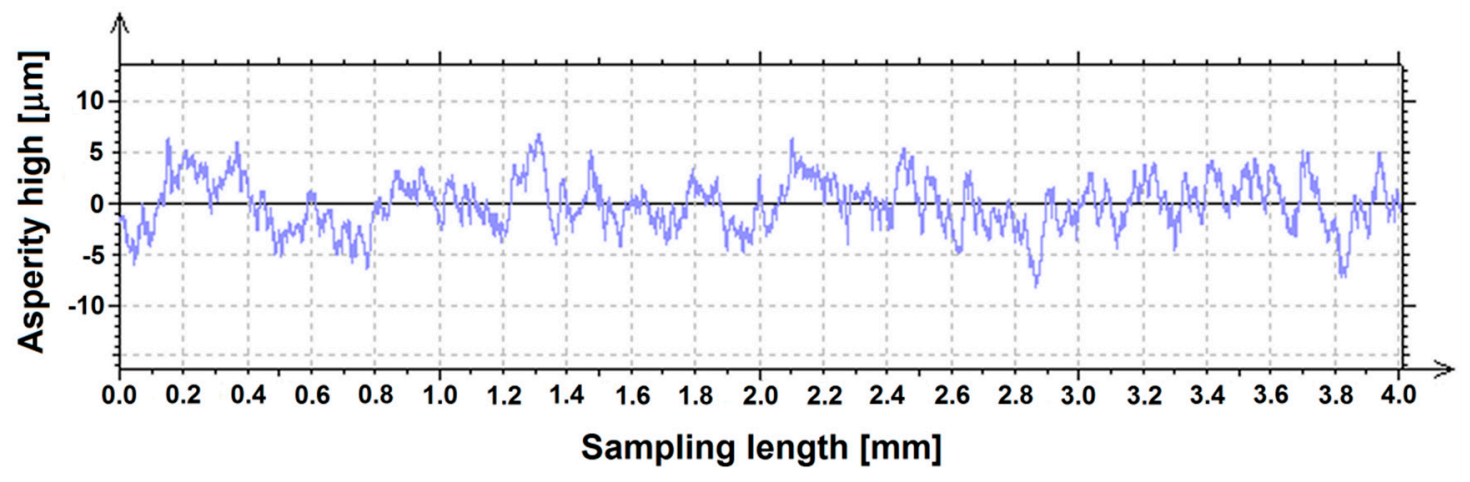

(a)

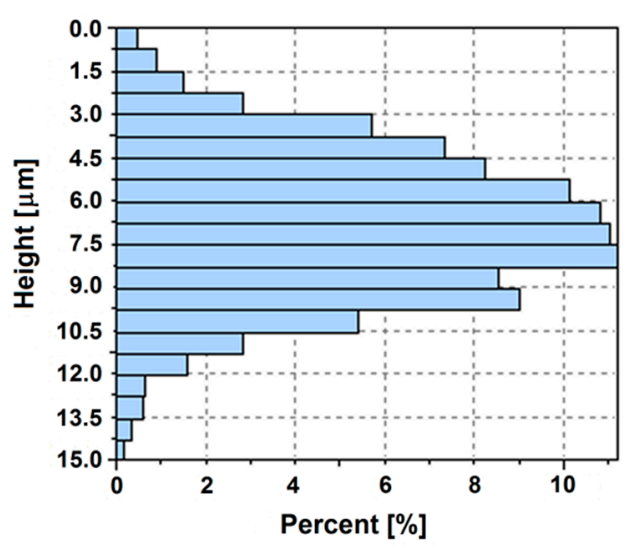

(b)

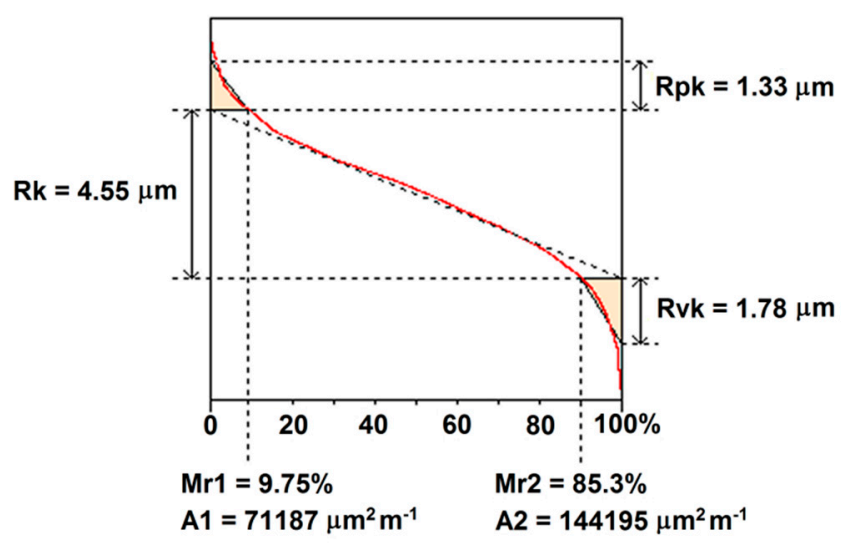

(c)

Figure 5. Sample profile recorded for the Ti G4 after sandblasting: (a) Roughness profile; (b) Distribution of the height ordinate; (c) Surface bearing area ratio curve.

\subsection{Surface Topography}

Surface topography plays a key role in determination of the functional performance of dental implants. However, surface topography characteristics based only on the registration of the 2D roughness profile, described by one or even several height parameters, is insufficient [61]. Complementary three-dimensional (3D) methods for the local measurement and understanding of surface topography are required. Recently, confocal laser scanning microscopy is used extensively in the field of biomaterials, especially for the characterization of surface irregularities and tests of surface topography in hypsometric colors that allow to read the location of hills and valleys in microareas. The depth of focus in the CLSM technique is controlled and highly limited [62].

Figure 6 shows surface topography maps in microareas for the sandblasted Ti G4 before and after sterilization from 30 to 120 min obtained using the CLSM. This optical imaging technique allowed to increase optical resolution and contrast of the micrographs through application of a spatial pinhole in order to block out-of-focus light in image formation. In the optical sectioning process, many 2D images were captured at various depths in the sample tested, which enabled the reconstruction of 3D structures. The surfaces of the Ti G4 subjected to sandblasting and autoclaving (Figure 6b-e) have a microstructure with predominance of deeper valleys compared to the less developed surface before autoclaving (Figure 6a). The results obtained could suggest a greater susceptibility to corrosion of more rough surfaces. However, it should be taken into account that such a clear relationship between 
2D/3D surface roughness parameters and a measurable index of functional surface characteristics, such as corrosion resistance, is typical of metals and alloys that are not in a passive state. The research challenge is to correlate the GSS parameters with the functional features of surfaces in the passive state like in case of the tested Ti G4, so that on the basis of these first measurements it is possible to predict the corrosion performance of the manufactured items.

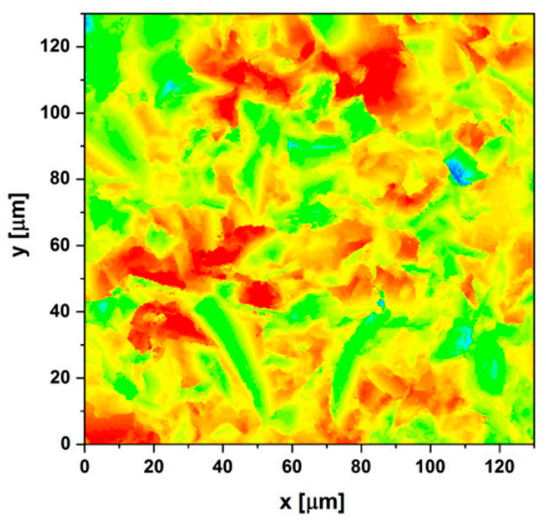

(a)

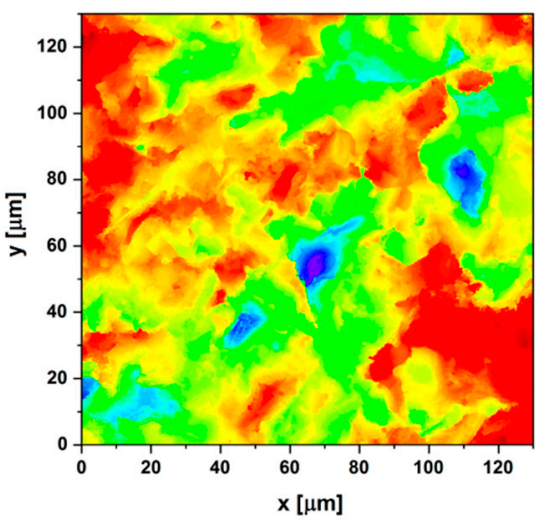

(c)
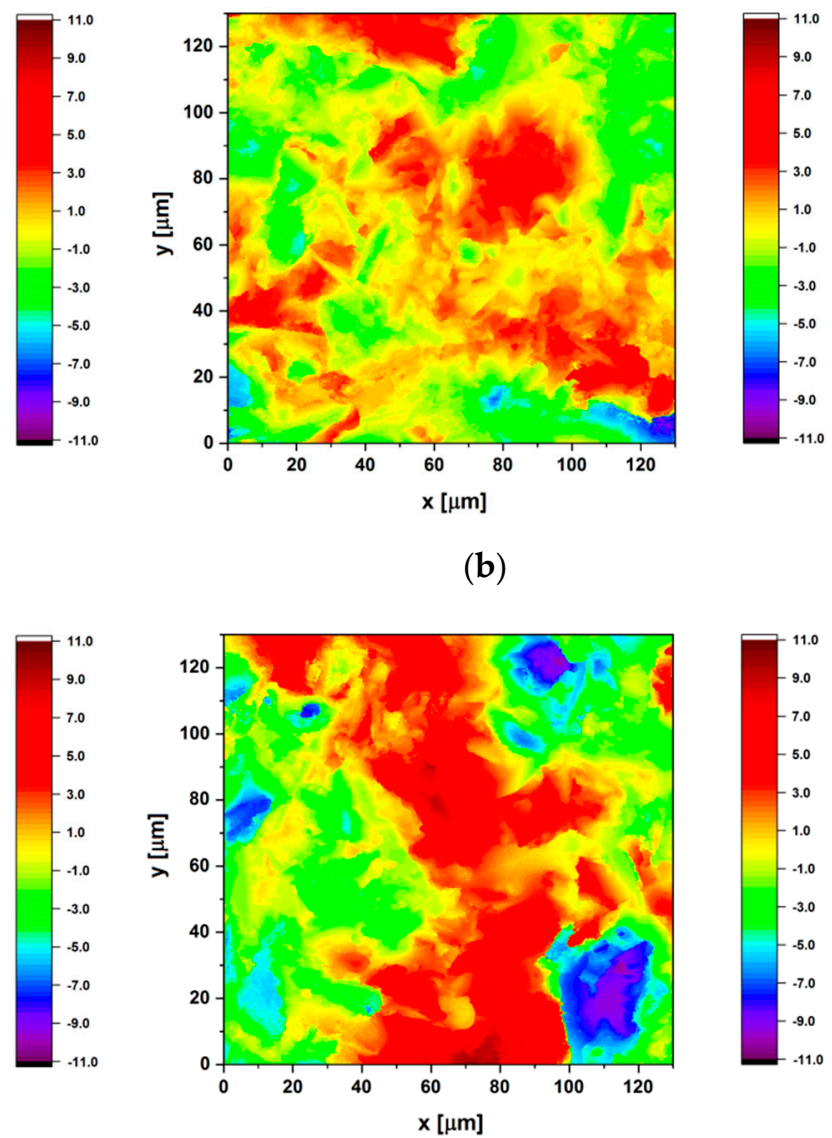

(d)

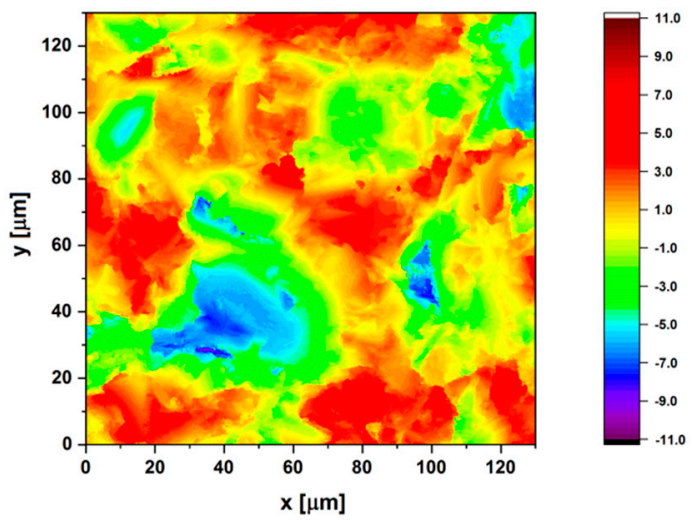

(e)

Figure 6. Surface topography map $\left(130 \times 130 \mu \mathrm{m}^{2}\right)$ obtained for the Ti G4 subjected to: (a) Sandblasting; (b) Sandblasting and autoclaving for $30 \mathrm{~min}$; (c) Sandblasting and autoclaving for $60 \mathrm{~min}$; (d) Sandblasting and autoclaving for $90 \mathrm{~min}$; (e) Sandblasting and autoclaving for $120 \mathrm{~min}$. 
The height parameters of surface roughness have the strongest impact on the intensity of corrosion due to increasing the real contact surface of the corrosive element. Therefore, based on the obtained surface topography maps, the Sa parameter value was calculated in accordance with ISO 25178-2 [63]. The $S a$ belonging to the category of height parameters denotes the arithmetic mean of the absolute value of the height from the mean plane of the surface. The determined values of the $S a$ parameter together with standard deviations obtained for the Ti G4 before and after autoclaving are presented in Table 7.

Table 7. Sa parameter defined as arithmetical mean height of the scale limited surface evaluated over the complete 3D surface in accordance with ISO 25178-2 [63] for the Ti G4 before and after autoclaving.

\begin{tabular}{ccc}
\hline Type of Sample & $S \boldsymbol{a}(\boldsymbol{\mu m})$ & SD \\
\hline Ti G4 sandblasted & 1.34 & 0.07 \\
\hline Ti G4 sandblasted and autoclaved for $30 \mathrm{~min}$ & 1.84 & 0.09 \\
\hline Ti G4 sandblasted and autoclaved for $60 \mathrm{~min}$ & 2.16 & 0.11 \\
\hline Ti G4 sandblasted and autoclaved for $90 \mathrm{~min}$ & 3.14 & 0.16 \\
\hline Ti G4 sandblasted and autoclaved for $120 \mathrm{~min}$ & 2.21 & 0.11 \\
\hline
\end{tabular}

The lowest value of $S a=1.34 \mu \mathrm{m}$ was obtained for the Ti G4 after sandblasting (Table 7). This 3D parameter has the same physical meaning as $R a=1.65 \mu \mathrm{m}$ determined during the 2D profilometric examination (Table 6). Therefore, the results obtained on the basis of the roughness profile with sampling length of $4 \mathrm{~mm}$ (Figure 5a) and the $130 \times 130 \mu \mathrm{m}^{2}$ surface topography map (Figure 6a) are comparable. This means that the surface topography of the analyzed sample is relatively homogeneous. The $S a$ parameter represents an overall measure of the texture comprising the surface. As a result of steam autoclave sterilization applied this height parameter value slightly increased due to formation of thin oxide layers on the surface of the sandblasted sample (Table 7). The optimal autoclaving time after which the largest development of the surface for the sandblasted Ti G4 was $90 \mathrm{~min}$.

\subsection{Open Circuit Potential Measurements}

The open circuit potential was used as a parameter determining the initial in vitro corrosion resistance of Ti G4 in a biological environment. The OCP method aimed to assess the protective properties of passive layers that arose as a result of sterilization in a steam autoclave on the sandblasted surface of the titanium electrode. Figure 7 illustrates the dependence of the open circuit potential for the sandblasted Ti G4 electrode before and after autoclaving on the immersion time $(t)$ in ASS at $37^{\circ} \mathrm{C}$.

The $E_{\mathrm{OC}}$ changed rapidly during the first $1500 \mathrm{~s}$ after immersing all electrodes in the ASS. The ionic-electron equilibrium on the electrode | ASS interface was reached after $120 \mathrm{~min}$, and then the stable value of $E_{\mathrm{OC}}$ was determined which was treated in further considerations as an approximate value of the $E_{\text {cor }}$. The lowest corrosion resistance was demonstrated by the Ti electrode after sandblasting for which the average value of $E_{\mathrm{OC}}$ was $-0.325(9) \mathrm{V}$. The most dynamic changes in the $E_{\mathrm{OC}}$ are observed for this electrode. This fact can be related to the presence of a self-passive oxide layer, which exhibits a discontinuous structure and is chemically unstable, and its barrier properties are insufficient. Initially, the $E_{\mathrm{OC}}$ significantly decreased over time due to very slow dissolution of the self-passive oxide layer or conversion of hydrated oxides into anhydrous oxides [37]. The $E_{\mathrm{OC}}$ then increased, suggesting the formation of an oxide layer on the electrode surface in the ASS or the sealing of an existing self-passive oxide layer on the Ti G4 surface. The average $E_{\mathrm{OC}}$ for all autoclaved titanium electrodes was more positive compared to the $E_{\mathrm{OC}}$ for the sandblasted Ti G4 before steam autoclave sterilization. Such a character of the $E_{\mathrm{OC}}$ changes suggests a decrement in the thermodynamic tendency to the corrosion of Ti G4. The average $E_{\mathrm{OC}}$ value changed with increasing autoclaving time from -0.193(5) V for Ti G4 electrode after $30 \mathrm{~min}$ of autoclaving to -0.060 (2) V for Ti G4 electrode after $120 \mathrm{~min}$ of autoclaving, respectively. The highest average $E_{\mathrm{OC}}$ of $-0.051(2) \mathrm{mV}$ was obtained for the Ti G4 electrode after 
90 min of autoclaving, which means that the obtained ultra-thin passive oxide layer revealed the strongest barrier properties. The obtained results show that the application of the autoclaving process has significantly improved the corrosion resistance of sandblasted Ti G4. The measurement conditions of the $E_{\mathrm{OC}}$ for the Ti G4 electrode before and after steam autoclave sterilization in the ASS at $37^{\circ} \mathrm{C}$ are very similar to the in vivo conditions in the human body.

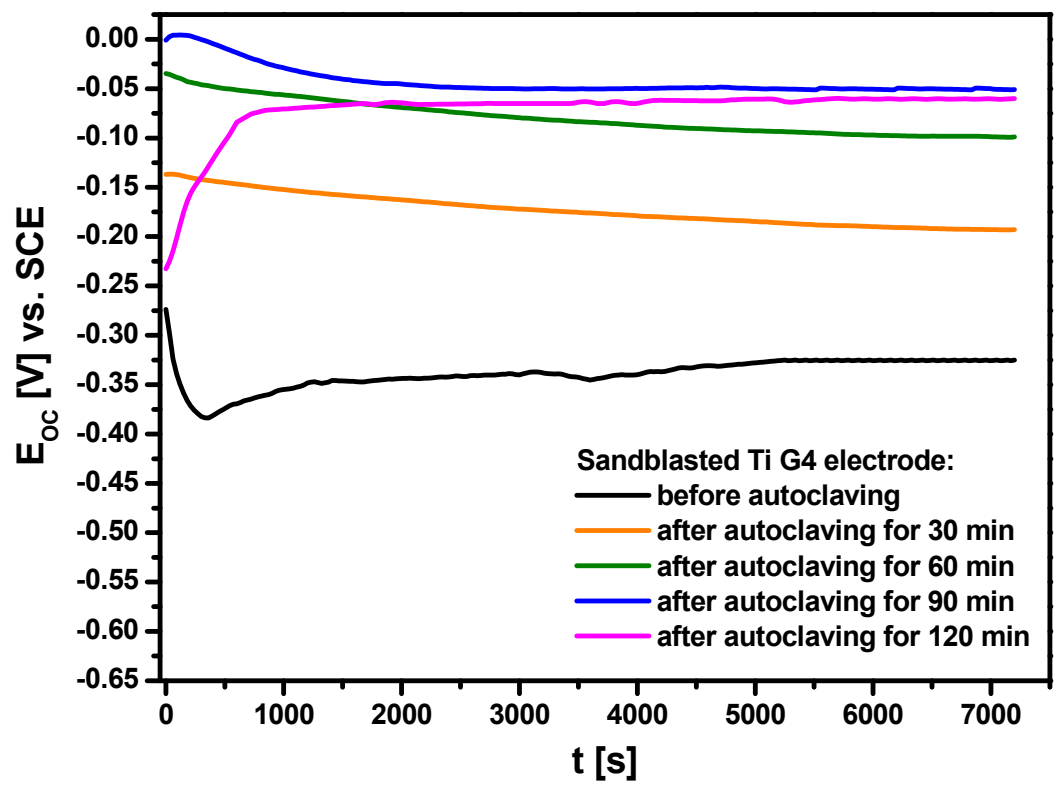

Figure 7. Open circuit potential as a function of immersion time for the sandblasted Ti G4 electrode in ASS at $37^{\circ} \mathrm{C}$.

\subsection{Polarization Curves Near the Open Circuit Potential}

The polarization curves for the sandblasted Ti G4 electrodes before and after autoclaving in the ASS at $37^{\circ} \mathrm{C}$ are shown in Figure 8. The electrochemical response of the tested electrodes was investigated near their open circuit potential. Within this narrow potential window of $\pm 50 \mathrm{mV}$ versus the $E_{\mathrm{OC}}$, the relationship between the potential and the logarithm of the current density module is linear. The obtained polarization curves closely mimic steady-state conditions due to a slow scan rate used. This method ensured the immediate measurement without the need to conduct long-term experiments in order to obtain a significant loss of the electrode mass. Corrosion resistance parameters determined based on the Tafel extrapolation of the polarization curves presented in Figure 8 are listed in Table 8.

Table 8. Corrosion resistance parameters determined based on the Tafel extrapolation method of the polarization curves for the Ti G4 electrodes before and after autoclaving immersed in ASS at $37^{\circ} \mathrm{C}$ (see Figure 8).

\begin{tabular}{|c|c|c|c|c|c|c|}
\hline Sandblasted Ti G4 & $\begin{array}{l}E_{\text {cor }} \\
\text { (V) }\end{array}$ & $\begin{array}{c}j_{\text {cor }} \\
\left(\mathrm{A} \mathrm{cm}^{-2}\right)\end{array}$ & $\begin{array}{c}b_{\mathrm{c}} \\
\left(\mathrm{V} \mathrm{dec}^{-1}\right)\end{array}$ & $\begin{array}{c}b_{\mathrm{a}} \\
\left(\mathrm{V} \mathrm{\textrm {dec } ^ { - 1 }}\right)\end{array}$ & $\begin{array}{c}R_{\mathrm{p}} \\
\left(\Omega \mathrm{cm}^{2}\right)\end{array}$ & $\begin{array}{l}C R \text { at } E_{\text {cor }} \\
\left(\mathrm{mm} \mathrm{yr}^{-1}\right)\end{array}$ \\
\hline Before autoclaving & $-0.337(5)$ & $2.88(30) \times 10^{-7}$ & $0.073(5)$ & $0.124(12)$ & $6.92 \times 10^{4}$ & $2.51 \times 10^{-3}$ \\
\hline $\begin{array}{l}\text { After autoclaving for } \\
\qquad 30 \mathrm{~min}\end{array}$ & $-0.189(5)$ & $3.55(3) \times 10^{-8}$ & $0.025(2)$ & $0.093(5)$ & $2.39 \times 10^{5}$ & $3.09 \times 10^{-4}$ \\
\hline $\begin{array}{l}\text { After autoclaving for } \\
60 \mathrm{~min}\end{array}$ & $-0.120(4)$ & $1.01(12) \times 10^{-7}$ & $0.058(6)$ & $0.324(77)$ & $2.10 \times 10^{5}$ & $8.77 \times 10^{-4}$ \\
\hline $\begin{array}{l}\text { After autoclaving for } \\
90 \mathrm{~min}\end{array}$ & $-0.077(4)$ & $5.67(3) \times 10^{-8}$ & $0.040(2)$ & $0.117(5)$ & $2.30 \times 10^{5}$ & $4.93 \times 10^{-4}$ \\
\hline $\begin{array}{c}\text { After autoclaving for } \\
120 \mathrm{~min}\end{array}$ & $-0.085(5)$ & $8.57(5) \times 10^{-8}$ & $0.034(2)$ & $0.158(10)$ & $1.42 \times 10^{5}$ & $7.46 \times 10^{-4}$ \\
\hline
\end{tabular}




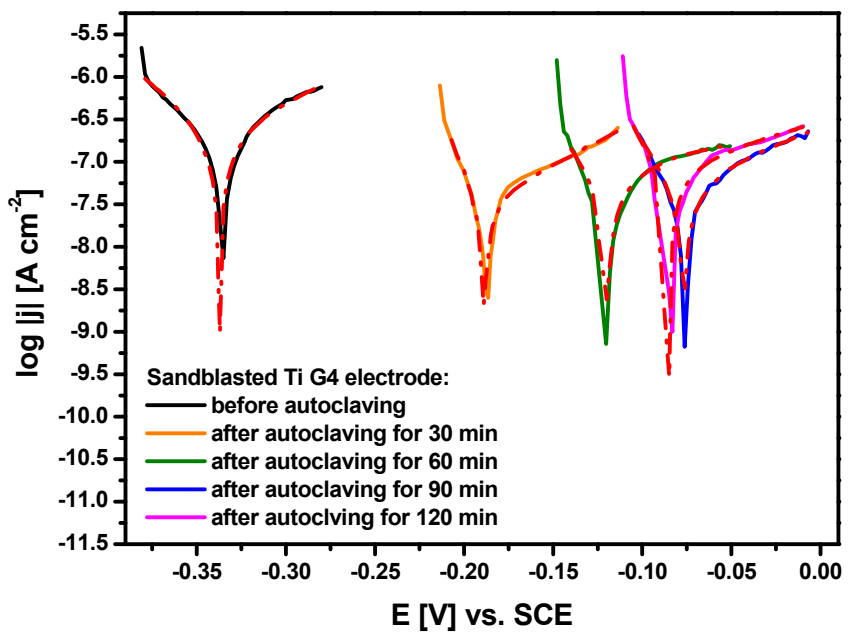

Figure 8. Polarization curves near the $E_{\mathrm{OC}}$ obtained for the sandblasted Ti G4 electrode before and after autoclaving in ASS at $37^{\circ} \mathrm{C}$. Experimental data are marked as continuous lines and fitted data using the Tafel extrapolation as red dash dotted lines.

The lowest average $E_{\text {cor }}$ value of $-0.337(5) \mathrm{V}$ is observed for the sandblasted Ti G4 electrode before steam autoclave sterilization. A slightly higher value of $E_{\text {cor }}$ was observed for sandblasted 35A commercially pure titanium in a $3.5 \% \mathrm{NaCl}$ solution at room temperature [24]. However, the authors used $\mathrm{SiO}_{2}$ particles of $200-300 \mu \mathrm{m}$ in diameter and recorded polarization curves with a scanning rate of $20 \mathrm{mV} \mathrm{min}{ }^{-1}$ for the sandblasting process. Figure 8 shows that autoclaving of the sandblasted Ti G4 caused the shift of the average $E_{\text {cor }}$ value towards the anode potentials. This electrochemical behavior is connected with an increase in corrosion resistance of the autoclaved electrodes due to the presence of the formed oxygen layers with stronger protective barrier properties as compared to the self-passive oxide layer. The highest average value of the $E_{\text {cor }}$ equal to $-0.077(4) \mathrm{V}$ was obtained for the sandblasted Ti G 4 after autoclaving for $90 \mathrm{~min}$ (Table 8). Based on the determined $E_{\text {cor }}$ values, it can be expected that the destructive processes will start fastest in the ASS on the sandblasted Ti G4 with a self-passive oxide layer on the electrode surface. These results correlate with the $S a$ parameter, which indicates the largest changes in the surface topography of the Ti G4 electrode after autoclaving for $90 \mathrm{~min}$, probably resulting from an increase in the thickness of the $\mathrm{TiO}_{2}$ layer (Table 7).

The highest average $j_{\text {cor }}$ value of $288(30) \mathrm{nA} \mathrm{cm}^{-2}$ is determined for the sandblasted Ti G4 electrode before autoclaving (Table 8). Significantly lower $j_{\text {cor }}$ values are observed for the sandblasted Ti G4 electrodes subjected to steam autoclave sterilization. Decreasing the average $j_{\text {cor }}$ value by almost 3-8 times depending on the autoclaving temperature indicates that the dissolution rate of the oxide layers formed by autoclaving occurs much slower as compared to the self-passive $\mathrm{TiO}_{2}$ layer. Although $j_{\text {cor }}$ is directly proportional to the dissolution rate of the oxide layer, it cannot be used as a kinetic parameter to compare the corrosion resistance of the Ti G4 before and after autoclaving.

The determined $b_{\mathrm{a}}$ Tafel slopes for all tested electrodes take significantly higher values in comparison with the values of $b_{\mathrm{c}}$ Tafel slopes (Table 8). This proves that the anode processes are faster than the cathode processes occurring at the corrosion potential, which is a mixed potential and both the reduction and oxidation processes affect its value. The Tafel slope depends on the parameters of the transition, including the construction of the transition complex or the number of exchanged electrons [64]. The Tafel slopes of the cathode and anode process can be expressed by formulas:

$$
\begin{gathered}
b_{\mathrm{c}}=-\frac{2.3 R T}{\alpha n F} \\
b_{\mathrm{a}}=\frac{2.3 R T}{(1-\alpha) n F}
\end{gathered}
$$


where $\mathrm{R}$ is the gas constant equal to $8.314 \mathrm{~J} \mathrm{~K}^{-1} \mathrm{~mol}^{-1}, \mathrm{~T}$ is the temperature in $\mathrm{K}, \alpha$ is the cathodic transfer coefficient, $\mathrm{n}$ is the number of electrons exchanged, and $\mathrm{F}$ is the Faraday constant equal to $96,500 \mathrm{C} \mathrm{mol}^{-1}$. From the values of the $b_{\mathrm{c}}$ and $b_{\mathrm{a}}$ coefficients, one can infer the mechanism of the electrode processes taking place.

The sandblasted Ti G4 before and after autoclaving is characterized by passive behavior which is typical of metal $(\mathrm{Me})$ covered by a metal oxide layer. Both the self-passive $\mathrm{TiO}_{2}$ layer and titanium oxide layers formed by autoclaving are oxidized very slowly in the ASS or thickening of the oxide layers occurs. The $\mathrm{TiO}_{2}$ layer is the kinetic factor which controls the corrosion rate of $\mathrm{Ti} \mathrm{G} 4$ in the ASS. The biocompatibility of Ti G4 dental metal is related to the stability of the $\mathrm{TiO}_{2}$ layer, which limits both the anodic and cathodic reactions and constitutes a physical barrier for ions transferred to the metal surface and an electronic barrier for electrons. During passive dissolution under anaerobic conditions in an aqueous solution, a charge transfer reaction takes place according to the following general reaction [65]:

$$
\mathrm{Me}+\mathrm{n} \cdot \mathrm{H}_{2} \mathrm{O} \leftrightarrow \mathrm{Me}(\mathrm{OH})_{\mathrm{n}}+\frac{\mathrm{n}}{2} \cdot \mathrm{H}_{2}
$$

Water plays the role of the oxidation agent. The products of reaction (4) may be metal oxides, hydroxides, or hydrated oxides and gaseous hydrogen.

Taking into account that the oxidation state IV $\left(\mathrm{Ti}^{4+}\right)$ is thermodynamically most stable form, the anodic process of titanium in aqueous solutions should be formally described by the reaction below [66]:

$$
\mathrm{Ti}+4 \mathrm{H}_{2} \mathrm{O} \leftrightarrow \mathrm{Ti}(\mathrm{OH})_{4}+2 \mathrm{H}_{2}
$$

However, $\mathrm{Ti}^{4+}$ is a very strong Lewis acid and is not able to exist in aqueous solutions due to deprotonations of $\mathrm{OH}^{-}$ions and $\mathrm{H}_{2} \mathrm{O}$ molecules. As a result, instead of the product in the form of $\mathrm{Ti}(\mathrm{OH})_{4}$ according to Reaction (5), more or less hydrated titanium(IV) oxide $\left(\mathrm{TiO}_{2} \cdot \mathrm{nH}_{2} \mathrm{O}\right)$ is formed as a stable end corrosion product.

The Reactions (4) and (5) are coupled with the oxidizing agent reduction which consumes electrons from the oxidation reaction. The Equations (6) and (7) take place in a neutral ASS environment:

$$
\begin{aligned}
& \mathrm{O}_{2}+2 \mathrm{H}_{2} \mathrm{O}+4 \mathrm{e}^{-} \rightarrow 4 \mathrm{OH}^{-} \\
& 2 \mathrm{H}_{2} \mathrm{O}+2 \mathrm{e}^{-} \rightarrow \mathrm{H}_{2}+2 \mathrm{OH}^{-}
\end{aligned}
$$

The major cathodic reaction in the AAS solution can be estimated on the basis of the corrosion potential determined for the Ti G4 electrodes before and after autoclaving (Table 8). From the Nernst equation for the hydrogen evolution reaction, $E_{\mathrm{H}^{+} / \mathrm{H}_{2}}=E_{\mathrm{H}^{+} / \mathrm{H}_{2}}^{0}-0.059 \mathrm{pH}$ [64] it was found that $E_{\mathrm{H}^{+} / \mathrm{H}_{2}}$ was equal to $-0.681 \mathrm{~V}$ vs. SCE at pH 7.4. The values of the $E_{\text {cor }}$ for all tested electrodes were more positive than the determined $E_{\mathrm{H}^{+} / \mathrm{H}_{2}}$ value (Table 8). This suggests that the hydrogen reduction was not a dominant cathodic reaction. In all cases seen in Table 8 , the rate of anodic reaction described by Equation (5) is faster than the reduction reactions illustrated by Equations (6) and (7). This suggests that the autoclaving does not change the nature of the electrochemical processes occurring at the Ti G4 electrode in the ASS.

The average value of $R_{\mathrm{p}}=6.92 \times 10^{4} \Omega \mathrm{cm}^{2}$ is the lowest for Ti G4 before autoclaving (Table 8). This results probably from a discontinuous structure and insufficient tightness of the self-passive $\mathrm{TiO}_{2}$ layer. The use of steam autoclave sterilization increases the polarization resistance by one order of magnitude indicating an improvement of the corrosion resistance of the autoclaved electrodes.

The calculated values of the $C R$ at the $E_{\text {cor }}$ for the Ti G4 before and after autoclaving are inversely proportional to the polarization resistance (Table 8). Among all the tested electrodes, the highest value of $C R=2.51 \times 10^{-3} \mathrm{~mm} \mathrm{yr}^{-1}$ is observed for Ti G4 with the self-passive oxide layer and represents the highest material consumption. The corrosion rate related to the dissolution of the $\mathrm{TiO}_{2}$ layers formed by autoclaving are one order of magnitude lower (Equation (5)). The passive layers formed by 
autoclaving more effectively impede the migration of Ti(IV) ions from the surface of Ti G4 to the ASS, thus minimizing corrosion process through reduction in material consumption.

\subsection{Electrochemical Impedance Spectroscopy Study}

Due to the fact that DC methods cannot be used to measure the charge transfer resistance $\left(R_{\mathrm{ct}}\right)$ across the interface of Ti G4|oxide layer|ASS, the study of the kinetics and mechanism of corrosion of the tested system was carried out using the complementary EIS method. This AC method has a great advantage over other electrochemical techniques because it allows to verify the quality of experimental data. The tool used to assess the correctness of the recorded data are the Kramers-Kronig relations. If the recorded data agree with the results obtained from the $\mathrm{K}-\mathrm{K}$ transformation, it means that they are formally correct and meet the conditions of good measurement, that is, causality, linearity, stability, and finiteness. The $\mathrm{K}-\mathrm{K}$ relations are based on the relation between the imaginary and real parts of the frequency dispersion, where each imaginary part, $Z_{\mathrm{im}}$, can be calculated from the real part, $Z_{\mathrm{re}}$, and vice versa. More details regarding the $\mathrm{K}-\mathrm{K}$ test can be found elsewhere [54,67].

The validity of raw EIS data for the Ti G4 before and after autoclaving has been confirmed using the $\mathrm{K}-\mathrm{K}$ test. Relative differences $\Delta_{\mathrm{re}, \mathrm{i}}$ and $\Delta_{\mathrm{im}, \mathrm{i}}$ between the experimental impedance data and the fit according to the $\mathrm{K}-\mathrm{K}$ test plotted against the log of the frequency did not exceed $10 \%$. For all impedance spectra, there was only a slight distribution of disturbances around the frequency axis, which indicated the data corresponded to $\mathrm{K}-\mathrm{K}$ relations. An exemplary deviation from the compliance with the $\mathrm{K}-\mathrm{K}$ relations for the sandblasted Ti G4 electrode is shown in the relative differences plot in Figure 9. The residuals in the entire range of tested frequencies are less than $8 \%$, thus the impedance spectra meet the $\mathrm{K}-\mathrm{K}$ relation, which proves the correctness of the recorded data. A noise distribution around the frequency axis is not observed in the high and medium frequency range. Only few points with large deviations in the range of low frequencies below $0.01 \mathrm{~Hz}$ were present, which could not be described by the $\mathrm{K}-\mathrm{K}$ transform, therefore they were not included in the detailed analysis of EIS spectra.

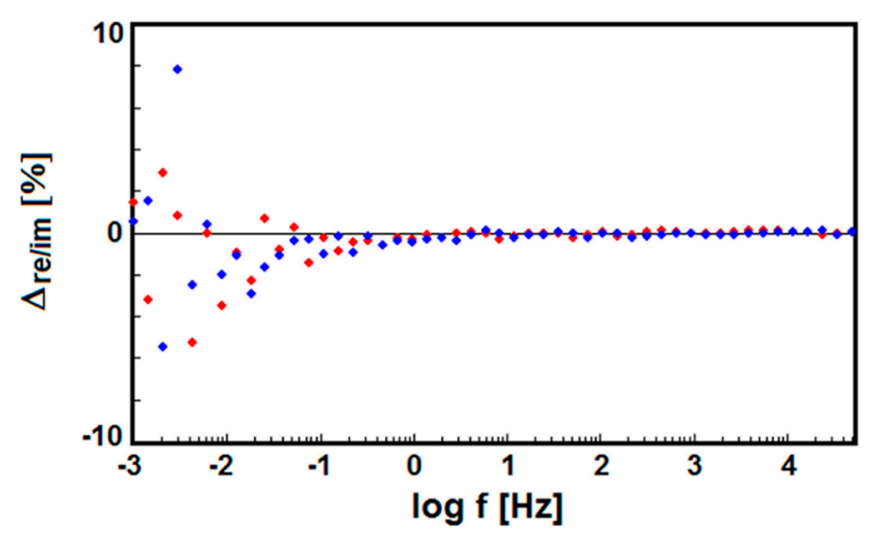

Figure 9. The K-K test residuals for a K-K test of the raw EIS data for the sandblasted Ti G4 electrode obtained at the $E_{\mathrm{cor}}$ in $\mathrm{ASS}$ at $37^{\circ} \mathrm{C}$. The red dots present the real part differences and the blue dots the imaginary part differences.

The experimental EIS data in the form of Bode diagrams marked with symbols are presented in Figure 10. Symbols in Figure 10a,b are the same. Bode diagrams illustrating the dependence of the $\log$ of the $|Z|$ as a function of the log of the frequency are characterized by a slope of the impedance module in the range of medium frequencies close to -1 (Figure 10a). An increase in the $\log |Z|$ value is observed at the lowest measuring frequency for all electrodes subjected to autoclaving, which proves the improvement of corrosion resistance as compared to the sandblasted Ti G4 electrode at the initial state in the following ascending order: electrode before autoclaving $>$ electrode after autoclaving for $30 \mathrm{~min}>$ electrode after autoclaving for $60 \mathrm{~min}>$ electrode after autoclaving for $120 \mathrm{~min}>$ electrode after autoclaving for $90 \mathrm{~min}$. Figure 10b shows experimental Bode diagrams in the form of phase 
angle $(\varphi)$ as a function of the log of the frequency. A plateau is seen in the medium frequency range. The independence of the phase angle from the frequency indicates the passive state Ti G4 provided by the oxide layers. The widest plateau is visible to the electrode after autoclaving for $90 \mathrm{~min}$, which confirms its highest corrosion resistance in the ASS. For all electrodes tested, the maximum values of $\varphi$ are about $10^{\circ}$ less than the ideal value of $-90^{\circ}$. One time constant is present in the electrical circuit, which is consistent with the literature data for titanium and its biomedical alloys covered by a thin oxide layer [40,47]. High values of $|\mathrm{Z}|_{\mathrm{f} \rightarrow 0}$ (Figure 10a) and $\varphi$ (Figure 10b) confirm the capacitive behavior of material characterized by high corrosion resistance.

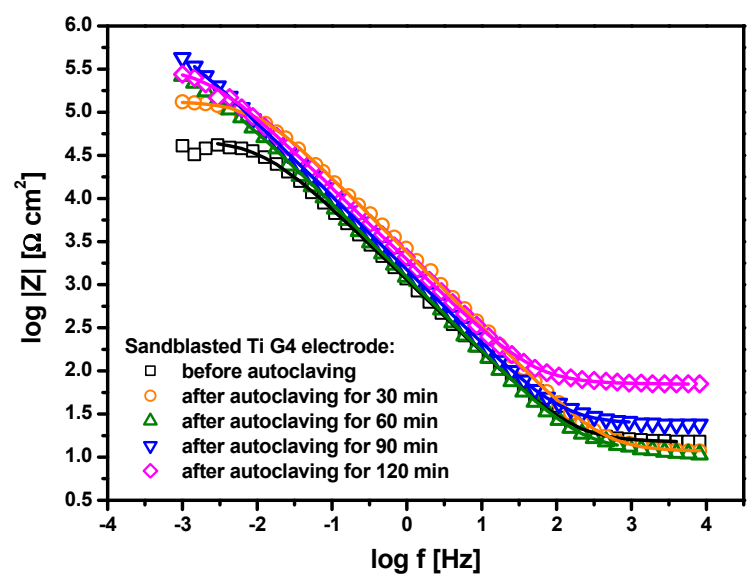

(a)

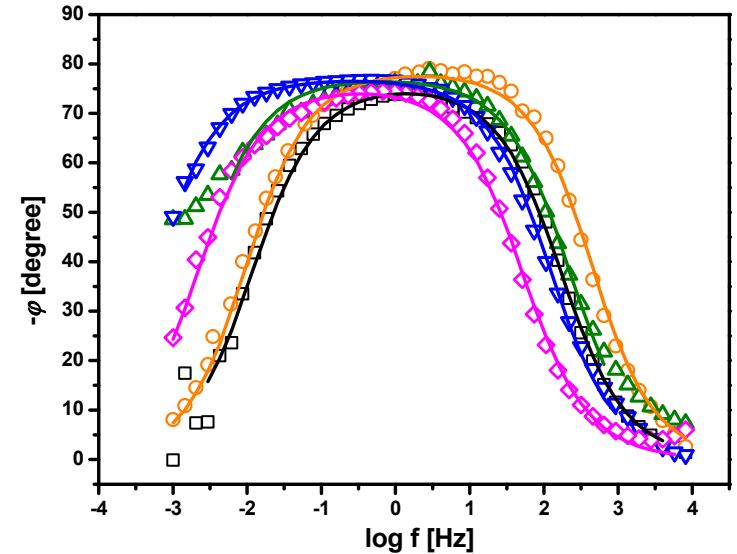

(b)

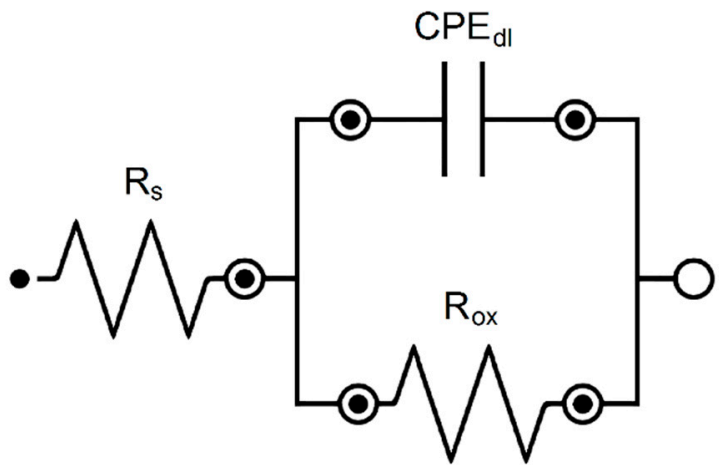

(c)

Figure 10. Bode diagrams obtained for the sandblasted Ti G4 electrode before and after autoclaving at $E_{\text {cor }}$ in ASS at $37^{\circ} \mathrm{C}$ : (a) Magnitude; (b) Phase angle; (c) Equivalent electrical circuit for the corrosion used to model the EIS data. Symbols are experimental data and continuous lines are CNLS fit.

In order to interpret the EIS results with respect to the barrier properties of the oxide layer, an approximation of the experimental AC data was carried out using the equivalent electrical circuit of modified Randle's cell shown in Figure 10c. This model for corrosion allows for simulating the response of the equivalent electrical circuit and then fitting the parameters of the circuit to the experimental EIS data using the CNLS method [54,67]. Each parameter has an assigned physicochemical meaning characterizing the impedance of Ti G4|TiO $2 \mid$ ASS interface. $R_{\mathrm{S}}$ is related to the solution resistance, $R_{\mathrm{ox}}$ represents the charge transfer resistance through the $\mathrm{TiO}_{2} \mid A S S$ interface, and the $\mathrm{CPE}_{\mathrm{dl}}$ is the constant phase element $(\mathrm{CPE})$ introduced instead of a capacitor which corresponds to the electrical double layer capacitance $\left(C_{\mathrm{dl}}\right)$. This procedure is typically used for ease of fitting for metallic materials coated with 
oxide layers due to the fact that EIS impedance diagrams deviate from the classical Randles' equivalent electrical circuit $[2,40,47,67]$. The impedance of the $\mathrm{CPE}\left(\hat{Z}_{\mathrm{CPE}}\right)$ is defined by the equation below:

$$
\hat{Z}_{\mathrm{CPE}}=\frac{1}{T(j \omega)^{\phi}}
$$

where $T$ is the capacitance parameter of the CPE expressed in $\mathrm{F} \mathrm{cm}^{-2} \mathrm{~s}{ }^{\phi-1}$, and $\phi$ is a CPE exponent related to the constant phase angle, $\alpha=90^{\circ}(1-\phi)$, which is dimensionless and takes values $\leq 1$ [67].

Calculations of the average $\bar{C}_{\mathrm{dl}}$ value were made using the following equation [68]:

$$
T=\bar{C}_{\mathrm{dl}}^{\phi}\left(\frac{1}{R_{\mathrm{S}}}+\frac{1}{R_{\mathrm{ox}}}\right)^{1-\phi}
$$

The fitted data using CNLS method and the electrical equivalent circuit presented in Figure 10c are marked as continuous lines in Figure 10a,b. A very good quality of fitting to the experimental EIS data was obtained. The values of all parameters resulting from the fitting using the equivalent electrical circuit illustrated in Figure 10c to approximate experimental EIS data obtained for the sandblasted Ti G4 electrode before and after autoclaving at the $E_{\text {cor }}$ in ASS at $37^{\circ} \mathrm{C}$ are summarized in Table 9.

Table 9. The value of parameters with their standard deviations obtained using the equivalent electrical circuit model for corrosion shown in Figure 11c to approximate the experimental EIS data for the

\begin{tabular}{|c|c|c|c|c|c|c|}
\hline Sandblasted Ti G4 & $\begin{array}{c}R s \\
\left(\Omega \cdot \mathrm{cm}^{2}\right)\end{array}$ & $\begin{array}{c}T_{\mathrm{dl}} \\
\left(\mathrm{F} \mathrm{cm}^{-2} \mathrm{~s}\right.\end{array}$ & $\phi_{d 1}$ & $\begin{array}{c}R_{\mathrm{ox}} \\
\left(\Omega \mathrm{cm}^{2}\right)\end{array}$ & $\begin{array}{c}\bar{C}_{\mathrm{dl}} \\
\left(\mathrm{F} \mathrm{\textrm {cm } ^ { - 2 }}\right)\end{array}$ & $\begin{array}{c}d_{\mathrm{ox}} \\
(\mathrm{nm})\end{array}$ \\
\hline Before autoclaving & $14.90(11)$ & $1.88(1) \times 10^{-4}$ & $0.844(2)$ & $4.81(7) \times 10^{4}$ & $6.30 \times 10^{-5}$ & 1.2 \\
\hline After autoclaving for $30 \mathrm{~min}$ & $11.64(14)$ & $8.49(7) \times 10^{-5}$ & $0.872(2)$ & $1.34(2) \times 10^{5}$ & $3.08 \times 10^{-5}$ & 1.3 \\
\hline After autoclaving for $60 \mathrm{~min}$ & $12.03(37)$ & $1.71(2) \times 10^{-4}$ & $0.858(3)$ & $2.30(23) \times 10^{5}$ & $6.13 \times 10^{-5}$ & 1.4 \\
\hline After autoclaving for $90 \mathrm{~min}$ & $24.24(13)$ & $1.41(1) \times 10^{-4}$ & $0.856(1)$ & $8.80(28) \times 10^{5}$ & $5.43 \times 10^{-5}$ & 2.0 \\
\hline After autoclaving for $120 \mathrm{~min}$ & $70.20(67)$ & $1.11(1) \times 10^{-4}$ & $0.840(2)$ & $3.36(8) \times 10^{5}$ & $4.39 \times 10^{-5}$ & 3.0 \\
\hline
\end{tabular}
sandblasted Ti G4 electrode before and after autoclaving in ASS at $37^{\circ} \mathrm{C}$.

The smallest value of $R_{\mathrm{ox}}$ is determined for the sandblasted Ti G4 electrode before autoclaving (Table 9). The use of steam autoclave sterilization affects the growth of $R_{\mathrm{ox}}$ by an order of magnitude. The highest value of $R_{\mathrm{ox}}=8.80(28) \times 10^{5} \Omega \cdot \mathrm{cm}^{2}$ was determined for the electrode after $90 \mathrm{~min}$ of autoclaving. The nature of changes in the $R_{\mathrm{ox}}$ parameter is in line with the values of $R_{\mathrm{p}}$ determined based on the Tafel extrapolation method (Table 8), which confirms the correctness of the obtained results. The physico-chemical meaning of the $R_{\text {ox }}$ parameter can be related to ongoing corrosion. The charge transfer resistance through the $\mathrm{TiO}_{2} \mid$ ASS interface according to Equation (5) takes larger values in case of the oxide layer formed by autoclaving, which show stronger barrier properties to aggressive chloride ions compared to the self-passive $\mathrm{TiO}_{2}$ layer. The spontaneously formed $\mathrm{TiO}_{2}$ layer is the least thermodynamically stable, possibly due to insufficient compactness, impermeability, and continuity of structure.

For all electrodes under test, the $\phi_{\mathrm{dl}}$ parameter shows a significant deviation from 1 (Table 9). It was reported that $\phi_{\mathrm{dl}}$ is an empirical parameter which is connected with the presence of physical, chemical or geometrical inhomogeneities [67]. Taking into account the obtained results of the GSS for the $\mathrm{Ti} \mathrm{G} 4\left|\mathrm{TiO}_{2}\right| \mathrm{ASS}$ system, the origin of the CPE dispersion can be related mainly to the surface microscopic roughness.

The calculated values of the $\bar{C}_{\mathrm{dl}}$ parameter are of the order of $10^{-5} \mathrm{~F} \mathrm{~cm}^{-2}$ for the electrodes after autoclaving and decrease compared to that for the Ti G4 electrode before autoclaving, which is evidence of the decreasing electrochemical activity (Table 9). Similar values of the $\bar{C}_{\mathrm{dl}}$ were reported in the literature for passivated titanium and its alloys in a biological environment $[40,47,48]$. 
The thickness of the oxide layer $\left(d_{\mathrm{ox}}\right)$ formed spontaneously and by autoclaving on the surface of $\mathrm{Ti}$ G4 electrode was calculated based on the EIS data using the equation given by Birch and Burleigh [69]:

$$
d_{\mathrm{ox}}=\varepsilon_{0} \varepsilon 2 \pi S f\left(Z-Z_{0}\right)
$$

where $\varepsilon_{0}$ represent the dielectric constant for free space equal to $8.854 \times 10^{-12} \mathrm{~F} \mathrm{~m}^{-1}, \varepsilon$ is the dielectric constant for $\mathrm{TiO}_{2}$ equal to $110, S$ denotes the area of the electrode surface, $f$ is the frequency at which the phase angle reaches its maximum, $Z$ stands for impedance at the frequency $f$, and $Z_{0}$ is the solution resistance. One can see that the calculated value of the $d_{\mathrm{ox}}$ increases with the autoclaving time from $1.2 \mathrm{~nm}$ for the sandblasted Ti G4 electrode with the self-passive oxide layer to $3.0 \mathrm{~nm}$ for the electrode after steam autoclave sterilization for $120 \mathrm{~nm}$ (Table 9).

\subsection{Scanning Kelvin Probe Measurements}

Effect of autoclaving time on work function for the sandblasted Ti G4 was determined using the SKP, which is a non-invasive method. The SKP is an analytical tool extremely sensitive to changes in the highest atomic layers caused by deposition, absorption, corrosion, wear and atomic displacement. Therefore, SKP can be treated as a "barometer" of the electrical properties of materials [55]. Surface distribution maps of the WF for the sandblasted Ti G4, before and after autoclaving, are pictured in Figure 11.

The maps ( $z$ variable) in Figure 11 were the basis to obtain the corresponding WF distribution histograms shown in Figure 12. Histograms were obtained by dividing the WF range into 30 intervals that were equal $(\Delta W)$ and determination of the $W F$ value, which lay in the interval of each interval $\left(n_{\mathrm{i}}\right)$. The function $\rho\left(W_{\mathrm{i}}\right)$ was approximated by $n_{\mathrm{i}} / \Sigma_{i} n_{\mathrm{i}} \Delta W$. It was assumed that the $\Delta W$ interval was small enough, and the $\rho\left(z_{\mathrm{i}}\right)$ was approximated by a continuous function $\rho(z)$, for which a Gaussian form was assumed. The Gaussian function described by the equation below was used for approximation of each histogram [70,71]:

$$
y=\frac{A}{\sigma \sqrt{2 \pi}} \mathrm{e}^{-\frac{(x-\bar{x})^{2}}{2 \sigma^{2}}}
$$

where $A$ represents a constant of $1, \sigma$ is the standard deviation, $\bar{x}$ denotes the average value of the Gaussian distribution expectation, i.e., a location of the $F W$ peak value, and $\sigma^{2}$ is the Gaussian distribution variance, i.e., a measure of the distribution width WF. The Gaussian distribution curves of the WF for the sandblasted Ti G4 before and after autoclaving are shown in Figure 12. The Gaussian fitting parameters of the WF are summarized in Table 10.

Table 10. Gaussian fitting parameters of the work function according to Equation (11) for the sandblasted Ti G4 before and after autoclaving.

\begin{tabular}{ccc}
\hline Sandblasted Ti G4 & $\bar{x}$ & \multicolumn{1}{c}{$\boldsymbol{\sigma}^{2}$} \\
\hline Before autoclaving & 3.98 & $(0.02)^{2}$ \\
\hline After autoclaving for 30 min & 4.03 & $(0.02)^{2}$ \\
\hline After autoclaving for $60 \mathrm{~min}$ & 4.22 & $(0.02)^{2}$ \\
\hline After autoclaving for 90 min & 4.31 & $(0.02)^{2}$ \\
\hline After autoclaving for $120 \mathrm{~min}$ & 4.28 & $(0.02)^{2}$ \\
\hline
\end{tabular}

In the case of the non-autoclaved Ti G4 sample, the average value of WF equals to $3.98 \mathrm{eV}$ (Table 10), which is the lowest amount of energy needed to release electrons from the surface of all tested materials. The determined value is close to the electron work function of $3.84 \mathrm{eV}$ for titanium reported by Kumar and co-workers [72]. On the other hand, the WF of $4.33 \mathrm{eV}$ for the polycrystalline titanium determined by photoelectric effect was determined [73]. Due to the fact that the WF depends on surface cleanliness, the results obtained often cover a wide range for individual metals. After the 
autoclaving process, the average WF increases, reaching the maximum value of $4.31 \mathrm{eV}$ for the sample autoclaved for $90 \mathrm{~min}$. The increase in $W F$ value for autoclaved samples may be related to the removal of organic and inorganic contaminant molecules during steam autoclave sterilization. Low values of $\sigma^{2}$ indicate that the $W F$ is close to a certain value and only changes slightly on the surface (Table 10). The obtained SKP data are in very good agreement with the electrochemical results.

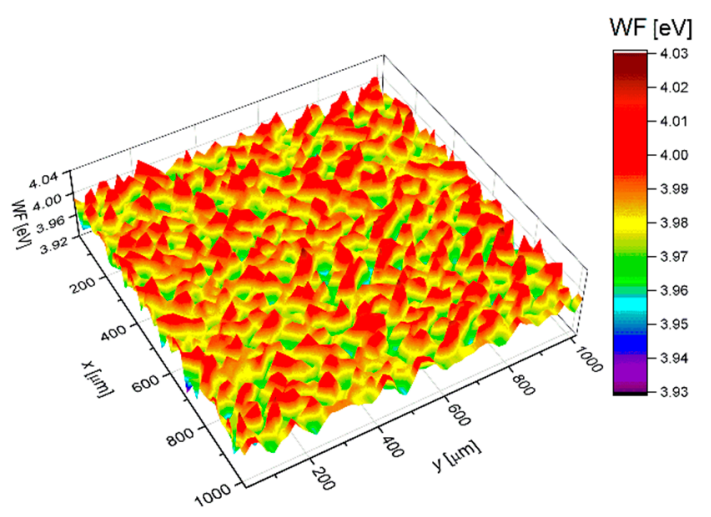

(a)

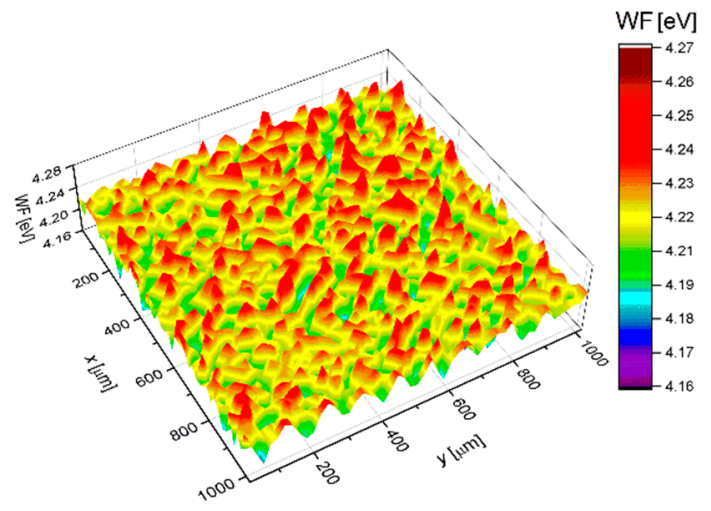

(c)

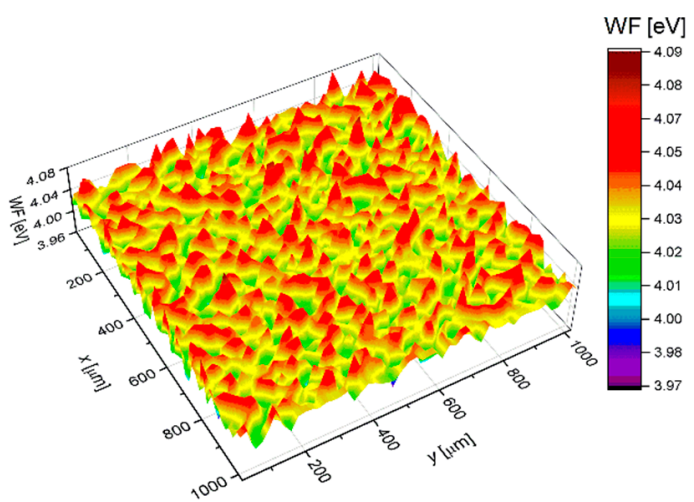

(b)

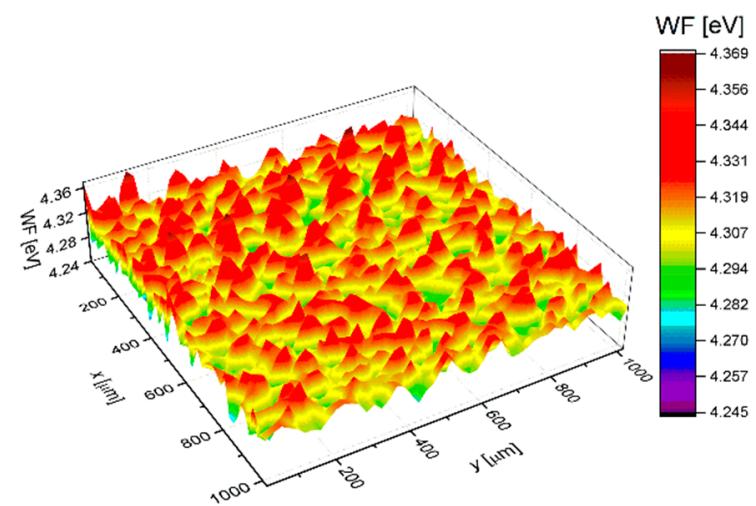

(d)

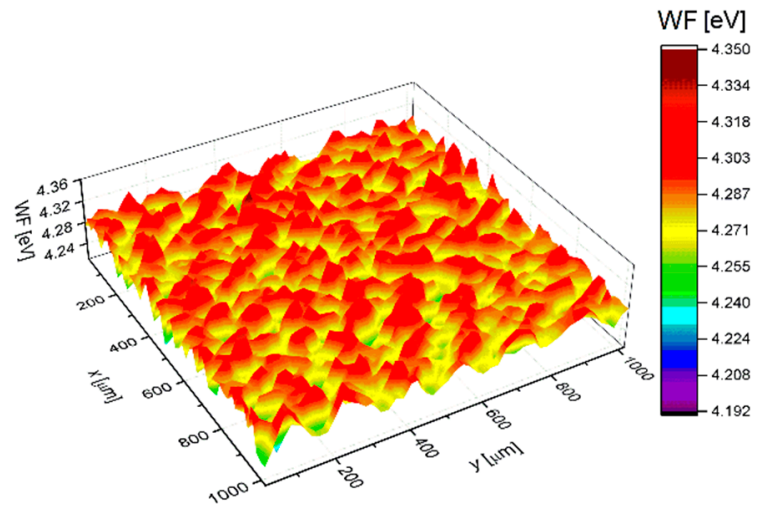

(e)

Figure 11. Surface distribution map of the work function for the sandblasted Ti G4: (a) Before autoclaving; (b) After autoclaving for $30 \mathrm{~min}$; (c) After autoclaving for $60 \mathrm{~min}$; (d) After autoclaving for $90 \mathrm{~min}$; (e) After autoclaving for $120 \mathrm{~min}$. 


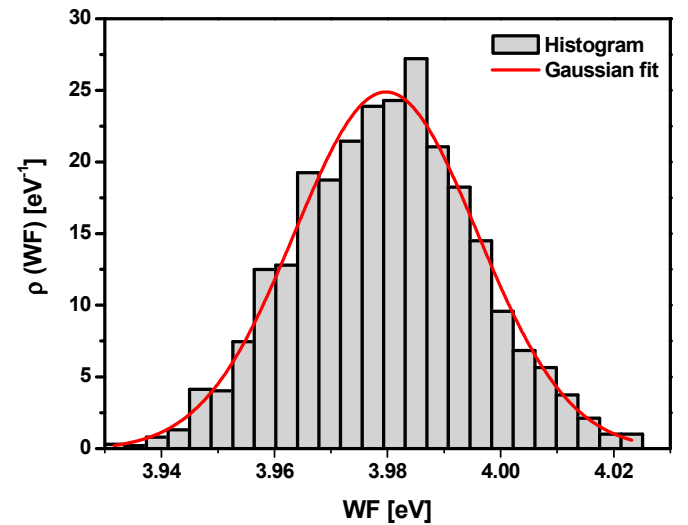

(a)

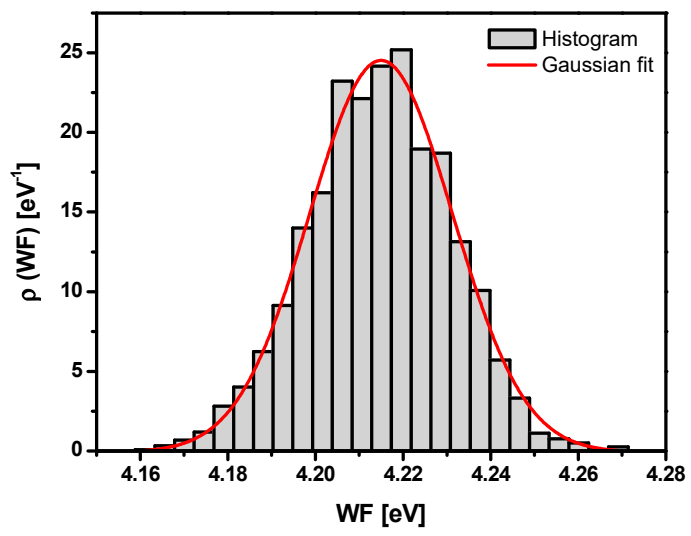

(c)

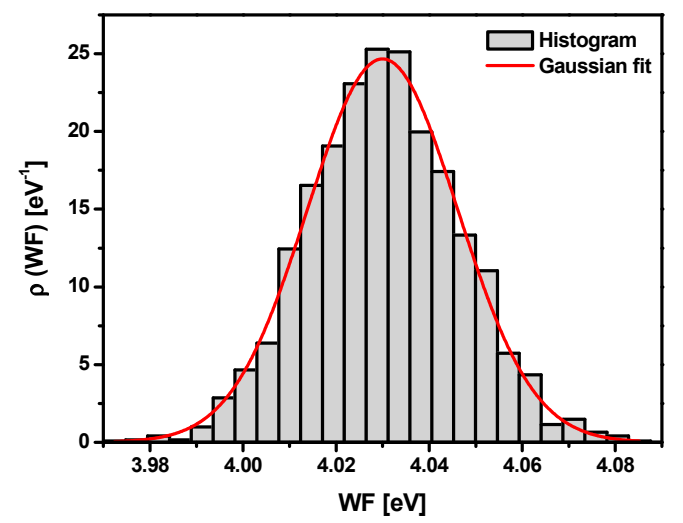

(b)

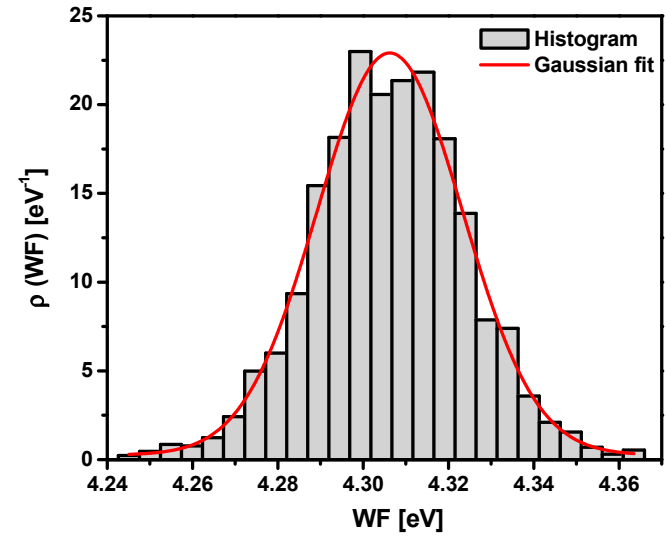

(d)

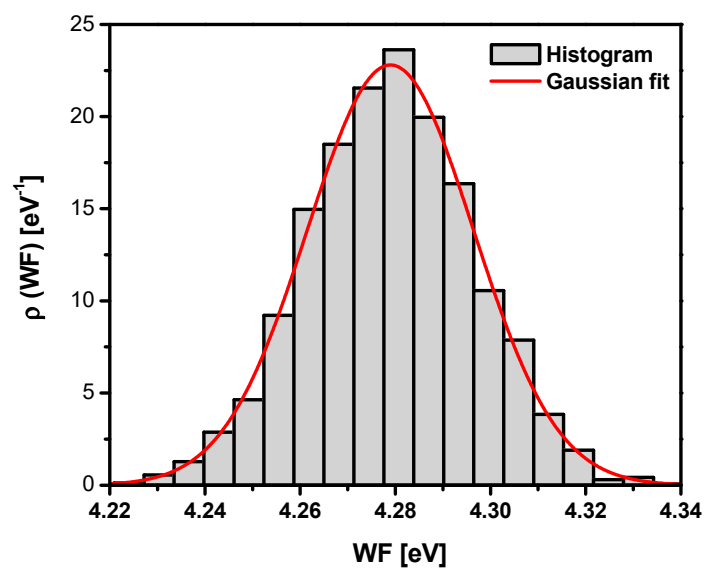

(e)

Figure 12. Work function distribution histogram and Gaussian fitting curve corresponding to Figure 11 for the sandblasted Ti G4: (a) Before autoclaving; (b) After autoclaving for $30 \mathrm{~min}$; (c) After autoclaving for $60 \mathrm{~min}$; (d) After autoclaving for $90 \mathrm{~min}$; (e) After autoclaving for $120 \mathrm{~min}$.

\section{Conclusions}

On the basis of the obtained results, it can be concluded that sterilization in a steam autoclave is an effective method of surface modification of the sandblasted Ti G4 dental metal, enhancing its corrosion resistance in the ASS with $\mathrm{pH}$ of 7.4 at $37^{\circ} \mathrm{C}$. The use of white $\mathrm{Al}_{2} \mathrm{O}_{3}$ particles for sandblasting process makes it possible to obtain the Ti G4 surface with a very high purity and optimal surface roughness for dental applications. The effect of the autoclaving time on in vitro corrosion resistance of 
the sandblasted Ti G4 was determined in electrochemical tests using the open circuit potential method, polarization curves, and electrochemical impedance spectroscopy. The improvement in the corrosion resistance was found after autoclaving due to the formation of passive oxide layers with high chemical stability. The thickness of the ultrathin oxide layers on the surface of Ti G4 was evaluated based on the $\mathrm{AC}$ impedance measurements in the range from $1.2 \mathrm{~nm}$ for the self-passive $\mathrm{TiO}_{2}$ layer to $3.0 \mathrm{~nm}$ for the passive oxide layer obtained after $120 \mathrm{~min}$ of autoclaving. The mechanism and kinetics of corrosion of the sandblasted Ti G4 before and after autoclaving was determined based on the EIS measurements fitted by the equivalent electrical circuit of modified Randle's cell, where $R_{\mathrm{S}}$ was related to the solution resistance, $R_{\mathrm{ox}}$ represented the charge transfer resistance through the $\mathrm{TiO}_{2} \mid \mathrm{ASS}$ interface, and the $C P E_{\mathrm{dl}}$ corresponded to the electrical double layer capacitance of the Ti G4-oxide layer-ASS interface. The capacitive behavior of materials characterized by high corrosion resistance was found. The increase in the electron work function after autoclaving confirmed the electrochemical results.

The optimal Ti G4 surface for dental applications can be obtained by sandblasting with white corundum with an average grain size of $53 \mu \mathrm{m}$, followed by autoclaving for $90 \mathrm{~min}$. Such a surface should be characterized by the parameter $S a$ of $3.14 \mu \mathrm{m}$, the presence of the oxide layer with a thickness of $2 \mathrm{~nm}$, and the electron work function of $4.31 \mathrm{eV}$, which will provide strong barrier properties to corrosion in ASS defined by: $E_{\text {cor }}$ of $-0.077 \mathrm{~V}, R_{\mathrm{p}}$ of $2.30 \times 10^{5} \Omega \cdot \mathrm{cm}^{2}, C R$ at the $E_{\text {cor }}$ of $4.93 \times 10^{-4} \mathrm{~mm}$ $\mathrm{yr}^{-1}$, and $R_{\mathrm{ox}}$ of $8.80 \times 10^{5} \Omega \cdot \mathrm{cm}^{2}$.

Author Contributions: Conceptualization, B.Ł.; methodology, B.Ł., J.M., P.O., J.K., and S.S.; investigation, P.O., J.M., J.K., and S.S; formal analysis, B.Ł., P.O., J.M., J.K., and S.S; writing-original draft preparation, B.Ł. and P.O.; writing-review and editing, J.M., J.K., and S.S; visualization, J.M., J.K., P.O., and S.S; funding acquisition, B.Ł. All authors have read and agreed to the published version of the manuscript.

Funding: This research was funded by the national research Innovation Incubator+ Project, grant No. 10/NAB3/II+/2017: "Functionalisation of titanium implant surfaces for applications in intelligent drug delivery systems" financed by the Minister of Science and Higher Education as part of a non-competitive project "Support for research management and commercialization of the results of works RED in scientific units and enterprises", implemented under the Intelligent Development Operational Program 2014-2020 (Action 4.4).

Acknowledgments: The authors wish to express their gratitude to Mirosław Grzegrzółka (University of Silesia in Katowice, Poland) for technical support with SEM/EDS measurements.

Conflicts of Interest: The authors declare no conflict of interest.

\section{References}

1. Nicholson, J.W. Titanium alloys for dental implants: A review. Prosthesis 2020, 2, 100-116. [CrossRef]

2. Gilbert, J.L. Electrochemical Behavior of Metals in the Biological Milieu. In Comprehensive Biomaterials II, 2nd ed.; Elsevier: Amsterdam, The Netherlands, 2017; pp. 19-49.

3. Lobat, T. Applications of Biomedical Engineering in Dentistry; Springer: Chem, Switzerland, 2020.

4. Verma, R.P. Titanium based biomaterial for bone implants: A mini review. Mater. Today Proc. 2020, 26, 3148-3151. [CrossRef]

5. Budmir, J.; Mravak-Stipetić, M.; Bulat, V.; Ferček, I.; Japundžić, I.; Lugović-Mihić, L. Allergic reactions in oral and perioral diseases-What do allergy skin test results show. Oral Surg. Oral Med. Oral Pathol. Oral Radiol. 2019, 127, 40-48. [CrossRef] [PubMed]

6. Chandu, G.S.; Hema, B.S.; Mahajan, H.; Mishra, S. Dental Metal Allergy: An Update. J. Res. Adv. Dent. 2014, 3, 156-163.

7. Brånemark, P.I.; Zarb, G.A.; Albrektsson, T. Tissue-Integrated Prostheses: Osseointegration in Clinical Dentistry, 1st ed.; Quintessence Publishing Company: Batavia, IL, USA, 1985.

8. Kapoor, N.; Nagpal, A.; Verma, R. Surface Treatment of Titanium Implant and Dental Implant Design: Titanium as Biomaterial and Method Used for Surface Treatment to Increase Bone and Soft Tissue Integration; LAP LAMBERT Academic Publishing: Beau-Bassin, Mauritius, 2020.

9. Le Guéhennec, L.; Soueidan, A.; Layrolle, P.; Amouriq, Y. Surface treatments of titanium dental implants for rapid osseointegration. Dent. Mater. 2007, 23, 844-854. [CrossRef] 
10. Singh, H.; Singh, S.; Prakash, C. Current trends in biomaterials and bio-manufacturing. In Biomanufacturing; Springer: Cham, Switzerland, 2019; pp. 1-34. [CrossRef]

11. Meng, H.W.; Chien, E.Y.; Chien, H.H. Dental implant bioactive surface modifications and their effects on osseointegration: A review. Biomark. Res. 2016, 4, 24. [CrossRef]

12. Nandal, S.; Ghalaut, P.; Shekhawat, H.; Nagar, P. Osseointegration in Dental Implants: A Literature Review. Med. Sci. 2014, 4, 411-413. [CrossRef]

13. Mokabber, T.; Zhou, Q.; Vakis, A.I.; van Rijn, P.; Pei, Y.T. Mechanical and biological properties of electrodeposited calcium phosphate coatings. Mater. Sci. Eng. C 2019, 100, 475-484. [CrossRef]

14. Alla, R.K.; Ginjupalli, K.; Upadhya, N.; Shammas, M.; Ravi, R.K.; Sekhar, R. Surface roughness of implants: A review. Trends Biomater. Artif. Organs 2011, 25, 112-118.

15. Wennerberg, A. The importance of surface roughness for implant incorporation. Int. J. Mach. Tools Manuf. 1998, 38, 657-662. [CrossRef]

16. De Bruyn, H.; Christiaens, V.; Doornewaard, R.; Jacobsson, M.; Cosyn, J.; Jacquet, W.; Vervaeke, S. Implant surface roughness and patient factors on long-term peri-implant bone loss. Periodontol. 2000 2017, 73, 218-227. [CrossRef] [PubMed]

17. Dank, A.; Aartman, I.H.A.; Wismeijer, D.; Tahmaseb, A. Effect of dental implant surface roughness in patients with a history of periodontal disease: A systematic review and meta-analysis. Int. J. Implant Dent. 2019, 5, 1-11. [CrossRef] [PubMed]

18. Haimov, H.; Yosupov, N.; Pinchasov, G.; Juodzbalys, G. Bone Morphogenetic Protein Coating on Titanium Implant Surface: A Systematic Review. J. Oral Maxillofac. Res. 2017, 8, 1-12. [CrossRef] [PubMed]

19. Bertoli, I.R.; Filgueira, M.; Ferreira, L.M.; de Sousa, L.L.; Mariano, N.A.; Ramos, A.S.; Nunes, C.A.; dos Santos, C.; Ramos, E.C.T. Microstructure and corrosion behavior in SBF medium of spark plasma sintered Ti- $x$ Zr-20Si-10B ( $x=5,7,10,15,20$ at.-\%) alloys. J. Alloys Compd. 2019, 797, 1157-1162. [CrossRef]

20. Simmons, C.A.; Valiquette, N.; Pilliar, R.M. Osseointegration of sintered porous-surfaced and plasma spray-coated implants: An animal model study of early postimplantation healing response and mechanical stability. J. Biomed. Mater. Res. 1999, 47, 127-138. [CrossRef]

21. Asri, R.I.M.; Harun, W.S.W.; Hassan, M.A.; Ghani, S.A.C.; Buyong, Z. A review of hydroxyapatite-based coating techniques: Sol-gel and electrochemical depositions on biocompatible metals. J. Mech. Behav. Biomed. Mater. 2016, 57, 95-108. [CrossRef]

22. Usinskas, P.; Stankeviciute, Z.; Beganskiene, A.; Kareiva, A. Sol-gel derived porous and hydrophilic calcium hydroxyapatite coating on modified titanium substrate. Surf. Coat. Technol. 2016, 307, 935-940. [CrossRef]

23. Cordioli, G.; Majzoub, Z.; Piatelli, A.; Scarano, A. Removal torque and histomorphometric investigation of 4 different titanium surfaces: An experimental study in the rabbit tibia. Int. J. Oral Maxillofac. Impants 2000, 15, 668-674.

24. Jiang, X.P.; Wang, X.Y.; Li, J.X.; Li, D.Y.; Man, C.-S.; Shepard, M.J.; Zhai, T. Enhancement of fatigue and corrosion properties of pure Ti by sandblasting. Mater. Sci. Eng. A 2006, 429, 30-35. [CrossRef]

25. Rupp, F.; Scheideler, L.; Olshanska, N.; de Wild, M.; Wieland, M.; Geis-Gerstorfer, J. Enhancing surface free energy and hydrophilicity through chemical modification of microstructured titanium implant surfaces. J. Biomed. Mater. Res. A 2006, 76, 323-334. [CrossRef]

26. Ellingsen, J.E.; Johansson, C.B.; Wennerberg, A.; Holmén, A. Improved retention and bone-tolmplant contact with fluoride-modified titanium implants. Int. J. Oral. Maxillofac. Implant. 2004, 19, 659-666.

27. London, R.M.; Roberts, F.A.; Baker, D.A.; Rohrer, M.D.; O'Neal, R.B. Histologic comparison of a thermal dualetched implant surface to machined, TPS, and HA surfaces: Bone contact in vivo in rabbits. Int. J. Oral. Maxillofac. Impants. 2002, 17, 369-376.

28. Albrektsson, T.; Wennerberg, A. Oral implant surfaces: Part 2-Review focusing on clinical knowledge of different surfaces. Int. J. Prosthodont. 2004, 17, 544-564. [PubMed]

29. Xu, S.; Xiaoyu, Y.; Yuan, S.; Minhua, T.; Jian, L.; Aidi, N.; Xing, L. Morphology improvement of sandblasted and acid-etched titanium surface and osteoblast attachment promotion by hydroxyapatite coating. Rare Met. Mater. Eng. 2015, 44, 67-72. [CrossRef]

30. Le Guehennec, L.; Lopez-Heredia, M.-A.; Enkel, B.; Weiss, P.; Amouriq, Y.; Layrolle, P. Osteoblastic cell behaviour on different titanium implant surfaces. Acta Biomater. 2008, 4, 535-543. [CrossRef] 
31. Schwarz, F.; Ferrari, D.; Herten, M.; Mihatovic, I.; Wieland, M.; Sager, M.; Becker, J. Effects of surface hydrophilicity and microtopography on early stages of soft and hard tissue integration at non-submerged titanium implants: An immunohistochemical study in dogs. J. Periodontol. 2007, 78, 2171-2184. [CrossRef]

32. Chen, F.; Lam, W.M.; Lin, C.J.; Qiu, G.X.; Wu, Z.H.; Luk, K.D.K.; Lu, W.W. Biocompatibility of electrophoretical deposition of nanostructured hydroxyapatite coating on roughen titanium surface: In vitro evaluation using mesenchymal stem cells. J. Biomed. Mater. Res. B Appl. Biomater. 2007, 82, 183-191. [CrossRef]

33. Buser, D.; Broggini, N.; Wieland, M.; Schenk, R.K.; Denzer, A.J.; Cochran, D.L.; Hoffmann, B.; Lussi, A.; Steinemann, S.G. Enhanced bone apposition to a chemically modified SLA titanium surface. J. Dent. Res. 2004, 83, 529-533. [CrossRef]

34. Jokstad, A.; Braegger, U.; Brunski, J.B.; Carr, A.B.; Naert, I.; Wennerberg, A. Quality of dental implants. Int. Dent. J. 2003, 53, 409-443. [CrossRef]

35. Das, K.; Bose, S.; Bandyopadhyay, A. Surface modifications and cell-materials interactions with anodized Ti. Acta Biomater. 2007, 3, 573-585. [CrossRef]

36. İzmir, M.; Ercan, B. Anodization of titanium alloys for orthopedic applications. Front. Chem. Sci. Eng. 2019, 13, 28-45. [CrossRef]

37. Simka, W.; Sadkowski, A.; Warczak, M.; Iwaniak, A.; Dercz, G.; Michalska, J.; Maciej, A. Characterization of passive films formed on titanium during anodic oxidation. Electrochim. Acta 2011, 56, 8962-8968. [CrossRef]

38. Park, J.W.; Lee, S.G.; Choi, B.J.; Suh, J.Y. Effects of a cell adhesion molecule coating on the blasted surface of titanium implants on bone healing in the rabbit femur. Int. J. Oral Maxillofac. Implant. 2007, 22, 533-541.

39. Özcan, M.; Hämmerle, C. Titanium as a reconstruction and implant material in dentistry: Advantages and pitfalls. Materials 2012, 5, 1528-1545. [CrossRef]

40. Osak, P.; Łosiewicz, B. EIS study on interfacial properties of passivated Nitinol orthodontic wire in saliva modified with Eludril ${ }^{\circledR}$ mouthwash. Prot. Met. Phys. Chem. Surf. 2018, 54, 680-688. [CrossRef]

41. Freitag, M.; Łosiewicz, B.; Goryczka, T.; Lelątko, J. Application of EIS to study the corrosion resistance of passivated NiTi shape memory alloy in simulated body fluid. Solid State Phenom. 2012, 183, 57-64. [CrossRef]

42. Serro, A.P.; Saramago, B. Influence of sterilization on the mineralization of titanium implants induced by incubation in various biological model fluids. Biomaterials 2003, 24, 4749-4760. [CrossRef]

43. Basiaga, M.; Walke, W.; Paszenda, Z.; Kajzer, A. The effect of EO and steam sterilization on the mechanical and electrochemical properties of titanium grade 4. Mater. Tehnol. 2016, 50, 153-158. [CrossRef]

44. Park, J.H.; Olivares-Navarrete, R.; Baier, R.E.; Meyer, A.E.; Tannenbaum, R.; Boyan, B.D.; Schwartz, Z. Effect of cleaning and sterilization on titanium implant surface properties and cellular response. Acta Biomater. 2012, 8, 1966-1975. [CrossRef]

45. Tanzi, M.C.; Farè, S.; Candiani, G. Sterilization and Degradation. In Foundations of Biomaterials Engineering, 1st ed.; Elsevier Science \& Technology: London, UK, 2019; pp. 289-328.

46. Mabboux, F.; Ponsonnet, L.; Morrier, J.J.; Benay, G.; Jaffrezic, N.; Barsotti, O. Effect of multiple desinfection/sterilization on surface characteristics of titanium based implants and in vitro bacterial adherence. Eur. Cells Mater. 2005, 9, 21-22.

47. Stróż, A.; Łosiewicz, B.; Zubko, M.; Chmiela, B.; Balin, K.; Dercz, G.; Gawlikowski, M.; Goryczka, T. Production, structure and biocompatible properties of oxide nanotubes on Ti13Nb13Zr alloy for medical applications. Mater. Charact. 2017, 132, 363-372. [CrossRef]

48. Smołka, A.; Dercz, G.; Rodak, K.; Łosiewicz, B. Evaluation of corrosion resistance of nanotubular oxide layers on the Ti13Zr13Nb alloy in physiological saline solution. Arch. Met. Mater. 2015, 60, 2681-2686. [CrossRef]

49. ISO. ISO 10271: Dentistry-Corrosion Test Methods for Metallic Materials; ISO: Geneva, Switzerland, 2011.

50. ISO. ISO 5832-2: Implants for Surgery-Metallic Materials-Part 2: Unalloyed Titanium; ISO: Geneva, Switzerland, 2018.

51. ASTM. ASTM F67-13: Standard Specification for Unalloyed Titanium, for Surgical Implant Applications (UNS R50250, UNS R50400, UNS R50550, UNS R50700); ASTM: West Conshohocken, PA, USA, 2017.

52. FEPA. FEPA standard 42-1: Macrogrits F4 F220 for Grains of Fused Aluminium Oxide, Silicon Carbide and Other Abrasive Materials for Bonded Abrasives; FEPA: Washington, DC, USA, 2006.

53. AUTOLAB. Electrochemical Instruments, Description of the Instrument; Eco Chemie, B.V., Ed.; Kanaalweg: Utrecht, The Netherlands, 1998.

54. Eco Chemie, B.V. Kanaalweg. In User Manual for Frequency Response Analysis (FRA) for Windows Version 4.9; Eco Chemie, B.V. Kanaalweg: Utrecht, The Netherlands, 2001. 
55. Łosiewicz, B.; Popczyk, M.; Szklarska, M.; Smołka, A.; Osak, P.; Budniok, A. Application of the scanning Kelivin probe technique for characterization of corrosion interfaces. Solid State Phenom. 2015, 228, 369-382. [CrossRef]

56. Tilghman, B.G. Improvement in Cutting and Engraving Stone, Metal, Glass, \&c. US Patent No. 108408, 18 October 1870.

57. Kasemo, B.; Lausmaa, J. Surface science aspects on inorganic biomaterials. Crit. Rev. Biocompat. 1986, 2, 335-380.

58. Díaz, I.; Pacha-Olivenza, M.Á.; Tejero, R.; Anitua, E.; González-Martín, M.L.; Escudero, M.L.; Garciía-Alonso, M.C. Corrosion behavior of surface modifications on titanium dental implant. In situ bacteria monitoring by electrochemical techniques. J. Biomed. Mater. Res. B Appl. Biomater. 2018, 106, 997-1009. [CrossRef] [PubMed]

59. ISO. ISO 4287: Geometrical Product Specifications (GPS)-Surface Texture: Profile Method-Terms, Definitions and Surface Texture Parameters; ISO: Geneva, Switzerland, 1997.

60. ISO. ISO 13565-2: Geometrical Product Specifications (GPS)-Surface Texture: Profile Method; Surfaces Having Stratified Functional Properties-Part 2: Height Characterization Using the Linear Material Ratio Curve; ISO: Geneva, Switzerland, 1996.

61. Pawlus, P.; Reizer, R.; Wieczorowski, M. A review of methods of random surface topography modeling. Tribol. Int. 2020, 152, 106530. [CrossRef]

62. Pawley, J.B. Handbook of Biological Confocal Microscopy, 3rd ed.; Springer Science+Business Media LLC: New York, NY, USA, 2006. [CrossRef]

63. ISO. ISO 25178-2: Geometrical Product Specifications (GPS)-Surface Texture: Areal-Part 2: Terms, Definitions and Surface Texture Parameters; ISO: Geneva, Switzerland, 2012.

64. Bard, A.J.; Faulkner, L.R. Electrochemical Methods. In Fundamentals and Applications, 2nd ed.; Wiley: New York, NY, USA, 2001.

65. Brunette, D.M.; Tengvall, P.; Textor, M.; Thomsen, P. Titanium in Medicine. In Material Science, Surface Science, Engineering, Biological Responses and Medical Applications; Springer: Berlin, Germany, 2001; pp. 145-162.

66. Pourbaix, M. Atlas of Electrochemical Equilibria in Aqueous Solutions, 2nd ed.; NACE International, National Association of Corrosion Engineers: Houston, TX, USA, 1974; ISBN 10-0915567989.

67. Lasia, A. Electrochemical Impedance Spectroscopy and its Applications; Springer Science+Business Media: New York, NY, USA, 2014. [CrossRef]

68. Brug, G.J.; Van den Eeden, A.L.G.; Sluyters-Rehbach, M.; Sluyters, J.H. The analysis of electrode impedances complicated by the presence of a constant phase element. J. Electroanal. Chem. 1984, 176, 275-295. [CrossRef]

69. Birch, J.R.; Burleigh, T.D. Oxides formed on titanium by polishing, etching, anodizing, or thermal oxidizing. Corrosion 2000, 56, 1233-1241. [CrossRef]

70. Kubisztal, J.; Kubisztal, M.; Haneczok, G. Quantitative characterization of material surface-Application to Ni + Mo electrolytic composite coatings. Mater. Charact. 2016, 122, 45-53. [CrossRef]

71. Kubisztal, J.; Kubisztal, M.; Stach, S.; Haneczok, G. Corrosion resistance of anodic coatings studied by scanning microscopy and electrochemical methods. Surf. Coat. Tech. 2018, 350, 419-427. [CrossRef]

72. Kumar, B.; Kaushik, B.K.; Negi, Y.S. Perspectives and challenges for organic thin film transistors: Materials, devices, processes and applications. J. Mater. Sci. Mater. Electron. 2014, 25, 1-30. [CrossRef]

73. Hölzl, J.; Schulte, F.K. Work Functions of Metals. In Solid Surface Physics; Springer: Berlin, Germany, 1979.

(C) 2020 by the authors. Licensee MDPI, Basel, Switzerland. This article is an open access article distributed under the terms and conditions of the Creative Commons Attribution (CC BY) license (http://creativecommons.org/licenses/by/4.0/). 